\title{
Principles of structural geology on rocky planets ${ }^{1}$
}

\author{
Christian Klimczak, Paul K. Byrne, A.M. Celâl Şengör, and Sean C. Solomon
}

\begin{abstract}
Although Earth is the only known planet on which plate tectonics operates, many small- and large-scale tectonic landforms indicate that deformational processes also occur on the other rocky planets. Although the mechanisms of deformation differ on Mercury, Venus, and Mars, the surface manifestations of their tectonics are frequently very similar to those found on Earth. Furthermore, tectonic processes invoked to explain deformation on Earth before the recognition of horizontal mobility of tectonic plates remain relevant for the other rocky planets. These connections highlight the importance of drawing analogies between the rocky planets for characterizing deformation of their lithospheres and for describing, applying appropriate nomenclature, and understanding the formation of their resulting tectonic structures. Here we characterize and compare the lithospheres of the rocky planets, describe structures of interest and where we study them, provide examples of how historic views on geology are applicable to planetary tectonics, and then apply these concepts to Mercury, Venus, and Mars.
\end{abstract}

Key words: planetary tectonics, planetary geology, Mercury, Venus, Mars.

Résumé : Bien que la Terre soit la seule planète connue sur laquelle il y a une tectonique des plaques, de nombreuses formes de relief tectoniques de petite et grande envergure indiquent que des processus de déformation se produisent également sur d'autres planètes rocheuses. Si les mécanismes de déformation sur Mercure, Vénus et Mars diffèrent, les manifestations en surface de leurs tectoniques respectives sont souvent très semblables à celles observées sur la Terre. En outre, des processus tectoniques invoqués pour expliquer la déformation sur la Terre avant la reconnaissance de la mobilité horizontale de plaques tectoniques revêtent toujours une pertinence pour les autres planètes rocheuses. Ces connexions soulignent l'importance d'établir des analogies entre les planètes rocheuses pour caractériser la déformation de leurs lithosphères et pour décrire, en appliquant la bonne nomenclature, et comprendre la formation des structures tectoniques en résultant. Nous caractérisons et comparons les lithosphères des planètes rocheuses, décrivons les structures d'intérêt et les lieux où elles sont étudiées, et présentons des exemples d'application de notions historiques à la tectonique planétaire pour ensuite appliquer ces concepts à Mercure, Vénus et Mars. [Traduit par la Rédaction]

Mots-clés : tectonique des planètes, géologie des planètes, Mercure, Vénus, Mars.

\section{Introduction}

Without a theoretical framework, such as the plate tectonic models, of the spatial relations of rock bodies to one another in an orogenic belt, however wrong they may be, objective criticism, fruitful deductions, and new observations would become difficult to make. Identifying terranes without immediate hypothetical interpretations diminishes testability (because tectonic analysis would be reduced to irrefutable singular existential statements) and therefore objectivity. I conclude that the terrane concept is therefore a less objective approach to orogeny than the simplistic models it criticizes and must inevitably lead to scientific sterility, as did the Alpine nappe concept before 1950. I argue for a methodology of tectonic analysis that starts with models about spatial relations of rock bodies and leads to piecemeal improvements by critical observations, a method that led to the discoveries of Alpine structure and evolution and also to plate tectonics. (A.M. Celâl Şengör, Lithotectonic terranes and the plate tectonic theory of orogeny: a critique of the principles of terrane analysis, 1990).
This argument by Şengör (1990a) - on the utility of the concept of terranes in the study of orogenic belts - could not be more fitting to many concepts and methods used in planetary structural geology and tectonics that have prevailed to the present.

The idea that similar processes generate similar outcomes underpins the principle of uniformitarianism that has made the rise of modern geology possible. However, uniformitarianism was originally invoked to explain structures that are now geologically inert. On Earth, there was no question that a given process created similar results everywhere. Curiously, this obvious point has often been overlooked in the justified excitement arising from the study of geological structures on other worlds. As space exploration revealed to us alien planetary surfaces, new designations were invented to catalogue the structures seen thereon. This approach was particularly true for the many shortening structures discovered on the rocky planets. Although the diversity and variability of structural styles and architecture of shortening structures on Earth are well documented, the nomenclature for extraterrestrial shortening landforms was established with no regard to testable descriptions clearly related to crustal shortening

Received 11 April 2019. Accepted 25 June 2019.

C. Klimczak. Department of Geology, University of Georgia, Athens, GA 30602, USA.

P.K. Byrne. Department of Marine, Earth, and Atmospheric Sciences, North Carolina State University, Raleigh, NC 27695, USA.

A.M.C. Şengör. Department of Geology, Faculty of Mines and the Eurasia Institute of Earth Sciences, İstanbul Technical University, 34469 Maslak, İstanbul, Turkey.

S.C. Solomon. Lamont-Doherty Earth Observatory, Columbia University, Palisades, NY 10964, USA.

Corresponding author: Christian Klimczak (email: klimczak@uga.edu).

'This paper is part of a Special Issue entitled "Understanding tectonic processes and their consequences: a tribute to A.M. Celâl Şengör".

Copyright remains with the author(s) or their institution(s). Permission for reuse (free in most cases) can be obtained from RightsLink. 
that were developed for Earth. Hence, comprehensive analogies between thrust systems on ours and other rocky worlds cannot be fully drawn in planetary structural geology.

Comparative geology as a method to study planets has long been known. Comparative earth science had been practiced ever since Aristotle, Dikaiarchos, Eratosthenes, and Strabo began describing the morphological features of our planet in terms of explanatory geological models, but the honor of systematizing comparative earth sciences, geography, and geology clearly belong to the two co-founders of modern geography, Carl Ritter and Alexander von Humboldt. Alexander von Humboldt combined his observations in Latin America with those in the Canary Islands, Europe, and western and central Asia to characterize the world's large tectonic features such as oceans, mountain belts, and large basins (such as the West Siberian or North Caspian) and to unite their description in one common terminology. His publications on global stratigraphy (von Humboldt 1823a) and on mountain ranges and volcanoes (von Humboldt 1823b, 1831, 1843) were aimed toward that end. Carl Ritter took a more systematic approach and compared the large-scale features of Asia among each other and helped to establish and expand von Humboldt's terminology in his monumental (if unfinished) "The General and Comparative Geography," of which only 19 volumes were published, covering Africa and almost the whole of Asia (see Richter 1983). Both von Humboldt and Ritter were aided by Leopold von Buch's earlier publications (von Buch 1810, 1824) on the isostatic rise of Scandinavia, the mountains of central Europe, and the volcanoes of the Canary Islands. When these authors' explanatory theories were refuted, a good part of their descriptive terminology survived into the time of the development of models involving substantial horizontal motions (e.g., Élie de Beaumont 1829-1830, 1852; Suess 1868, 1875, 1883, 1885, 1888, 1901, 1909a, 1909b), and the new terminology, much enriched through the first three decades of the twentieth century (e.g., Argand 1911, 1912, 1924, 1926, 1934; Kober 1921, 1931, 1942; Stille 1924, 1940; Staub 1924, 1928; Bucher 1933), proved extremely helpful in describing and interpreting the large-scale structural features of our planet. However, after World War II, that terminology and hypothetical world view of tectonics gradually fell into desuetude, largely because of the switch of the international scientific language from French and German to English alone and the rise of an unwelcome diffidence towards theorizing in geology. By the time of the advent of plate tectonics theory, beginning with J. Tuzo Wilson's epoch-making paper of 1965 (Wilson 1965), much of the older, rich, and very apposite terminology had been forgotten. Consequently, such studies, for reasons mentioned above, have been ignored in the planetary science community.

In this paper, we elaborate on some widely accepted principles and techniques of structural geology devised by the Earth tectonic community that can be readily applied to the study of planetary tectonics, but which have not yet found widespread use for worlds beyond our own. Likewise, some forgotten principles and techniques developed for Earth prior to the wide scientific acceptance of plate tectonics find applicability on one-plate planets (i.e., those with a single, continuous lithospheric shell) such as Mercury and Mars. Of course, comparative planetary geology must account for differences between Earth and other planets, such as the presence of water, which affects mineralogical and rheological aspects of tectonic processes, as well as other foundational differences, including planetary size, internal constitution, and thermal structure. With these differences in mind, we show with a series of examples that analogies between tectonics on Earth and tectonics on other rocky planets, as well as among the rocky planets themselves, can be made and testable interpretations of landforms can be formulated.

General problems with practices in planetary tectonics are not limited only to the description of landforms without an associated interpretation, but also include a lack of widely accepted and practiced standards for tectonic mapping across the community, the introduction of new terms to describe and interpret structures or processes when relevant terminology is already established for such structures or processes on Earth, and the introduction of countless schemes of classifications and categorizations of morphological variations of one landform type on a single planetary body. In particular, the lack of standards and resulting inconsistencies across tectonic mapping within the planetary tectonics community has led to a range of maps and related analyses ranging from too conservative to over-interpreted. Furthermore, the interpretations of the origin and formation of planetary tectonic structures that introduces sets of new terms separate from the established structural descriptions not only serve to disconnect two communities in one scientific field, but also fail to recognize a wide selection of terrestrial analogue sites for planetary tectonic structure.

Planetary tectonic landforms and processes can be better understood at Earth analogue field sites, and can be described as such with the terminology and techniques traditionally used in structural geology and tectonics on Earth, particularly because early principles developed prior to the recognition of plate tectonics are well suited and still relevant for planets with no plate tectonics. At the same time, planetary processes inform our understanding of Earth's geologic history in the context of prevalent tectonic styles both prior to and during the era of modern-day plate tectonics. With ongoing advancements in technology, data products, and visualization across the fields of structural and planetary geology (Huntington and Klepeis 2018), the increasing volume of science collaborations and communications requires shared understanding and use of existing standard terms and language in structural geology.

The categorization of tectonic landforms on the basis of morphological characteristics is a common method to attempt to systematize findings in planetary tectonics (e.g., Dzurisin 1978; Watters et al. 2009), with categories frequently established by drawing arrows on images pointing to the tectonic structures that best fit the category. This method, however, can be problematic for interpretations when the categorization is carried out without placing landforms into their broader tectonic context. Indeed, without doing so, we encounter again the problem that analogies between multiple sets of structures cannot be properly drawn when criteria are inconsistently applied or are too narrow to capture the natural variability of tectonic structures and processes, or when structures occur on a morphological continuum and no single criterion (or set of criteria) can describe and fully distinguish between discrete landforms. The latter point is highlighted in Hans Cloos' well-drawn series of block diagrams (Cloos 1936) that showcase spatial connections of structure types on Earth (Fig. 1). The diagrams capture the thinking of the time prior to the discovery of plate tectonics, in that a genetic continuum of mountain ranges exists within a tectonic setting dominated by global contraction - a process later found to have governed tectonics on Mercury, the Moon, and Mars (e.g., Solomon 1977).

In this paper, we present a comparison of general lithospheric structures, and we highlight the rheological properties of the terrestrial planets that are important for understanding their tectonics. We then describe a series of structures of interest and importance to the study of tectonics on Earth in map and (or) cross-sectional view. The list of structures discussed in this writing is by no means exhaustive, but rather is intended to highlight how our understanding of such structures on Earth can be applied to select tectonic settings on Mercury, Venus, and Mars.

\section{The lithospheres of the terrestrial planets}

Comparative planetary tectonic analysis must start by understanding the differences among and similarities between the structures of the planetary lithospheres, i.e., the outermost shell 
Fig. 1. Series of block diagrams, from Cloos (1936), showing a continuum of structures that could exist within a tectonic setting dominated by global contraction. This figure is in the public domain.

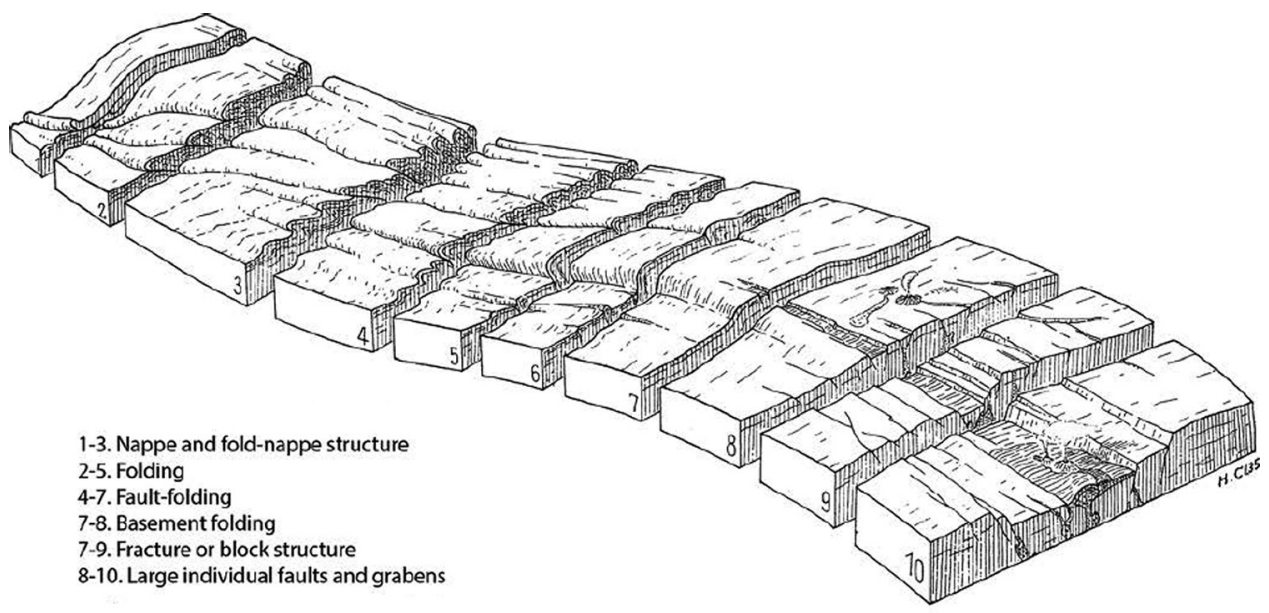

of the solid planet that carries a long-term record of its deformation. While planetary crusts and mantles are distinguished by chemical composition, the term "lithosphere" refers to a planet's mechanically strong outer shell, in which stresses can build up to the point that tectonic processes come into play. Planetary lithospheres are frequently characterized by their "elastic thickness," which describes the effective thickness of the lithosphere that can support stresses elastically over geological time scales. Although this concept is of importance for geophysical characterization of elastic (recoverable) responses to tectonic stresses in lithospheres, our focus on geologic structures involving jointing, faulting, and folding relies on plastic (permanent) lithospheric deformation. The lithospheric structure of a planet involves both brittle and ductile behaviors and is determined by the deformational and strength properties of the rocks forming the lithosphere. These factors govern the size and style of fault zones, the support of topography and thus the size and shape of tectonic landforms, and the magnitude of stresses needed to drive plastic deformation.

A lithosphere includes both brittle and ductile regimes, in which deformation is accommodated by localized fracturing processes and distributed plastic flow, respectively. Brittle deformation can occur in the coldest regions of each layer in the lithosphere. The brittle strength of the lithosphere, a measure of the amount of stress that can be withstood by the lithosphere without failure, is dominated by the frictional properties of the rock volume and the surface gravitational acceleration of the planet. Under the assumption that brittle lithospheres generally contain fractures of all orientations, stresses there must overcome the frictional resistance to sliding for rock failure to occur along a fracture plane of optimal orientation (e.g., Byerlee 1978). Byerlee's law and the Mohr-Coulomb criterion (e.g., Handin 1969) are both used to assess lithospheric strength to describe to first order the linear increases with depth in peak stresses. Byerlee's law, in particular, is widely used in planetary tectonics to characterize the frictional resistance to sliding in lithospheres for intermediateand high-pressure conditions (Brace and Kohlstedt 1980). The strengths of brittle portions of lithospheres are mostly insensitive to mineralogy or temperature.

At depth, where temperatures are sufficiently high to activate plastic deformation micromechanisms, such as dislocation creep or diffusion creep (e.g., Passchier and Trouw 2005), rocks behave in a ductile manner via plastic flow (e.g., Kohlstedt and Mackwell 2010). Ductile strength is strongly dependent on temperature, pressure, mineralogy, the type of rheological processes activated, grain size, melt fraction, the presence or absence of water, and strain rate (e.g., Kohlstedt et al. 1995), resulting in marked decreases with increasing depth. Ductile strength models are sensitive to the thermal gradient and are often assumed to be governed by a constant strain rate, a uniform lateral distribution of deformation, and a flow law inferred from laboratory measurements of material of a single mineralogy, typically the one displaying the weakest rheology. None of these simplifying assumptions is likely to be strictly correct, but together they permit approximations to actual behavior that have been widely applied.

Combining brittle and ductile strength models provides an approximate profile of strength versus depth, or strength envelope, that defines the entire lithosphere. Strength envelopes are useful for estimating total lithospheric thickness, the depth interval of the transition from brittle to ductile deformation, and the stresses at any depth within the lithosphere that are required for deformation to occur - and so they are invaluable for comparative tectonics of the rocky planets. Figure 2 shows a compilation of possible model solutions of strength envelopes for the modern lithospheres of the four inner solar system planets. Differential stresses are the difference between horizontal and vertical principal stresses, and their positive and negative values (with compression here defined as positive) correspond to lithospheric strength in tectonic regimes undergoing shortening and extension, respectively. In addition to the information about the lithosphere contained in each individual strength envelope, their presentation as a group allows comparisons to be drawn between them that have implications for the nature and expression of tectonics on each of these planets.

Three possible lithospheric structures are shown for Mercury (Fig. 2). Brittle portions of the strength envelopes are modified from Klimczak (2015), and the ductile behavior is shown for flow laws of dry diabase (crust) and dunite (mantle) with a strain rate of $10^{-19} \cdot \mathrm{s}^{-1}$ described by thermally activated power-law relations between differential stress and strain from the nominal temperature structure of Mercury modeled by Williams et al. (2011). All envelopes are plotted for a crustal thickness of $40 \mathrm{~km}$, consistent with Mercury's gravity and topography (Padovan et al. 2015). The contrasting strength envelopes arise from insolation-driven differences in the upper parts of temperature-depth profiles of the planet (Williams et al. 2011) associated with surface temperature variations (Vasavada et al. 1999) that result from the planet's 3:2 spin-orbit resonance. The surface temperatures are lowest $\left(147^{\circ} \mathrm{K}\right)$ at the rotational poles, the highest surface temperatures $\left(427^{\circ} \mathrm{K}\right)$ are at equatorial hot poles located at $0^{\circ}$ and $180^{\circ} \mathrm{E}$, and intermediate surface temperatures $\left(324^{\circ} \mathrm{K}\right)$ are at the equatorial cold poles at $90^{\circ}$ and $270^{\circ} \mathrm{E}$. On the basis of these regional temper- 
Fig. 2. Lithospheric strength envelopes of the terrestrial planets calculated for present geophysical and mineralogical properties and known or inferred crust and mantle characteristics. Rock columns in the center of the strength envelopes indicate flow laws for the dominant mineralogy, with Earth showing continental and oceanic rock columns on the left and right, respectively. The sources for each set of strength envelopes are given in the text. (Figure compiled after Klimczak 2015, Williams et al. 2011, Ghail 2015, Kohlstedt et al. 1995, Mackwell et al. 1998, and Grott and Breuer 2008.) [Color online.]

\section{Differential stress $(\mathrm{GPa})$}

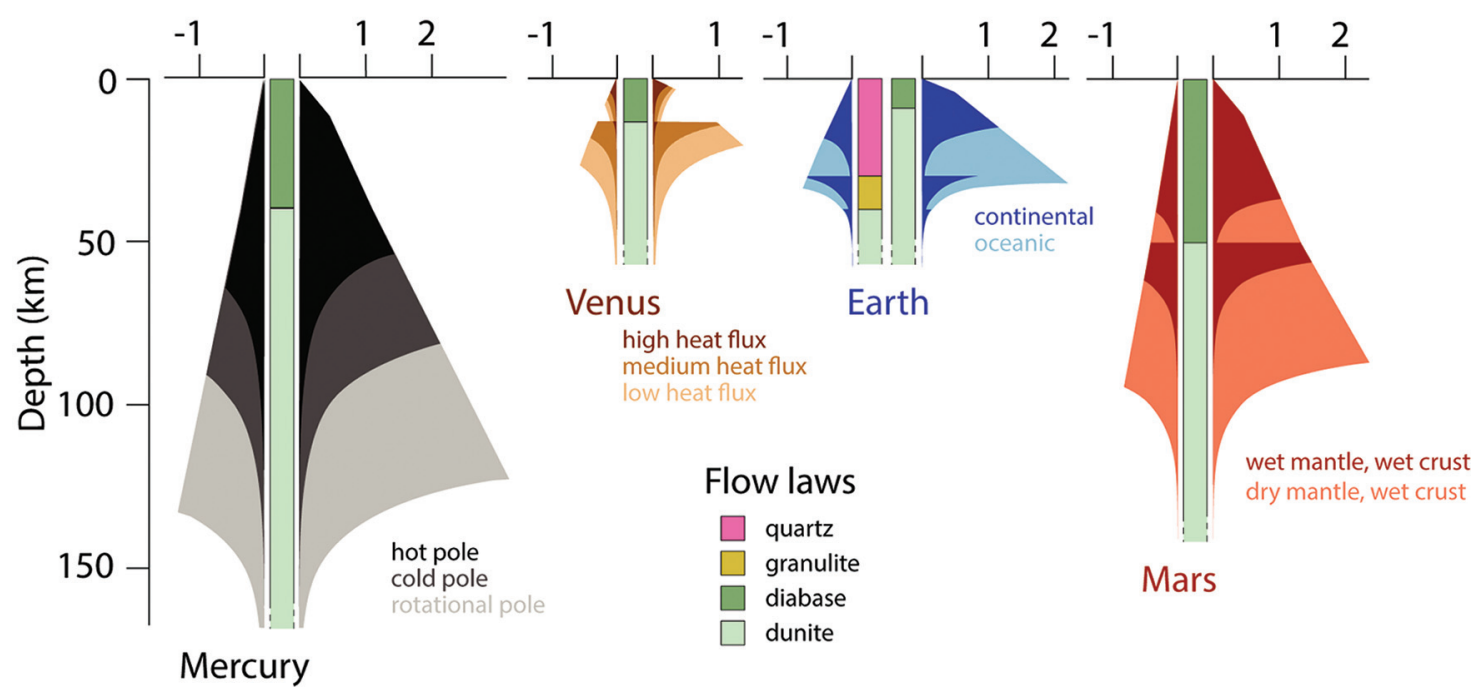

ature variations, Mercury's modern lithosphere shows a total thickness ranging from $100 \mathrm{~km}$ at the hot poles to in excess of $150 \mathrm{~km}$ at the rotational poles (Fig. 2). The lithosphere is characterized by a thick brittle portion that transitions to the portions dominated by ductile behavior at depths globally exceeding $\sim 50 \mathrm{~km}$, but at the rotational poles such transitional behavior is not reached until depths of $120 \mathrm{~km}$. These strength envelopes suggest that much of the recent tectonics on Mercury has been controlled by the brittle strength of the crust and upper mantle.

For Venus, the three solutions for present lithospheric structure shown in Fig. 2 are modified after strength envelopes presented by Ghail (2015), with updated curves for Byerlee's law of intermediate- and high-pressure friction (e.g., Schultz 1993). Ductile (power-law) creep is modeled for strain rates of $10^{-15} \cdot \mathrm{s}^{-1}$ and crust and mantle rheologies dominated by dry diabase and dunite, respectively. The differences in the strength envelopes arise solely from different assumptions regarding heat flow of 12, 18, and $36 \mathrm{~mW} \cdot \mathrm{m}^{-2}$ (see Ghail (2015) for justification on the temperaturedepth profiles of Venus). Whatever the actual mean heat flow on Venus, the planet's high surface temperature limits the lithosphere to be no thicker than $30-70 \mathrm{~km}$ and leads to a weak zone in the lower crust (Fig. 2). As parameters for flow laws on Venus are poorly constrained by observation, it cannot be judged from solutions to strength envelopes alone whether such a low-strength zone is of sufficient thickness or weakness to result in tectonic decoupling of the crust and mantle (Ghail 2015), or whether surface tectonics are coupled to strain through the entire lithosphere (Kohlstedt and Mackwell 2010).

Earth has two distinct types of lithospheres, caused by the different thicknesses and compositions of the oceanic and continental crust. One possible solution of lithospheric structure is shown in Fig. 2 for each type of lithosphere. Strength envelopes were calculated and modified after solutions presented by Kohlstedt et al. (1995) for the oceanic lithosphere (Fig. 2, light blue) and by Mackwell et al. (1998) for the continental lithosphere (Fig. 2, dark blue). Both profiles are for a strain rate of $10^{-15} \cdot \mathrm{s}^{-1}$ and are derived from temperature-depth relationships after Chapman (1986) for continental settings, and after Turcotte and Schubert (2002) for oceanic settings. Differences between these two solutions of strength envelopes arise only from variations in crustal thickness and assumptions regarding the weakest major mineral and its ductile flow law. The strength of oceanic lithosphere is modeled for a wet diabase crust and wet dunite mantle, whereas the continental lithosphere is modeled for an upper crust dominated by wet quartz, a lower crust of wet granulite (feldspar), and a wet dunitic mantle (Kohlstedt et al. 1995; Mackwell et al. 1998). The total modeled thickness for both types of lithosphere under these assumptions is $\sim 60 \mathrm{~km}$, but lithospheric thickness on Earth is known to vary, as young oceanic lithosphere may be as thin as a few kilometres whereas cratonic roots in continental lithosphere may reach depths in excess of $200 \mathrm{~km}$ (Pasyanos 2010). Nonetheless, the particular solutions to strength envelopes for Earth in Fig. 2 suggest that substantial strength resides in the continental crust and the oceanic crust and upper oceanic mantle, and that it is those parts that likely participate in modern tectonics.

Generic strength envelopes for modern conditions on Mars were compiled after Grott and Breuer (2008), given their model solutions for temperature-depth profiles and strain rates of $10^{-17} \cdot \mathrm{s}^{-1}$ for rheologies appropriate to wet diabase compositions for the crust and wet (Fig. 2, dark red) or dry (Fig. 2, salmon) dunite compositions for the mantle. Differences between these two solutions arise solely from the different assumptions about the water content of the mantle. These solutions for the lithospheric structure of Mars imply that tectonics on the Red Planet are controlled by the strength residing in both the crust and upper mantle.

Given the wide parameter space for the derivation of strength envelopes, with many parameters poorly constrained by observations, and the simplifying assumptions regarding mineralogy, rheology, strain rate, and crustal thickness, as well as changes in the parameters over time, the strength envelopes of the rocky planets presented here represent only a few of many plausible solutions for each body. And although direct comparison between these particular solutions (Fig. 2) must be made with great care, the differences in governing parameters that lead to similarities among and differences in the lithospheric structures hold clues for interpreting and comparing the manifestations of tectonic landforms and processes across the rocky planets.

Differences among the lithospheric structures of Mercury, Venus, Earth, and Mars (Fig. 2) in the brittle regime are attributable mainly to differences in the surface gravitational acceleration, 
Fig. 3. Annotated diagram of upright folds, showing the geometry of an anticline-syncline pair and their respective map symbologies. A series of anticlines at the bottom of the diagram indicates different fold tightness, from gentle or open, to tight and isoclinal shapes. [Color online.]

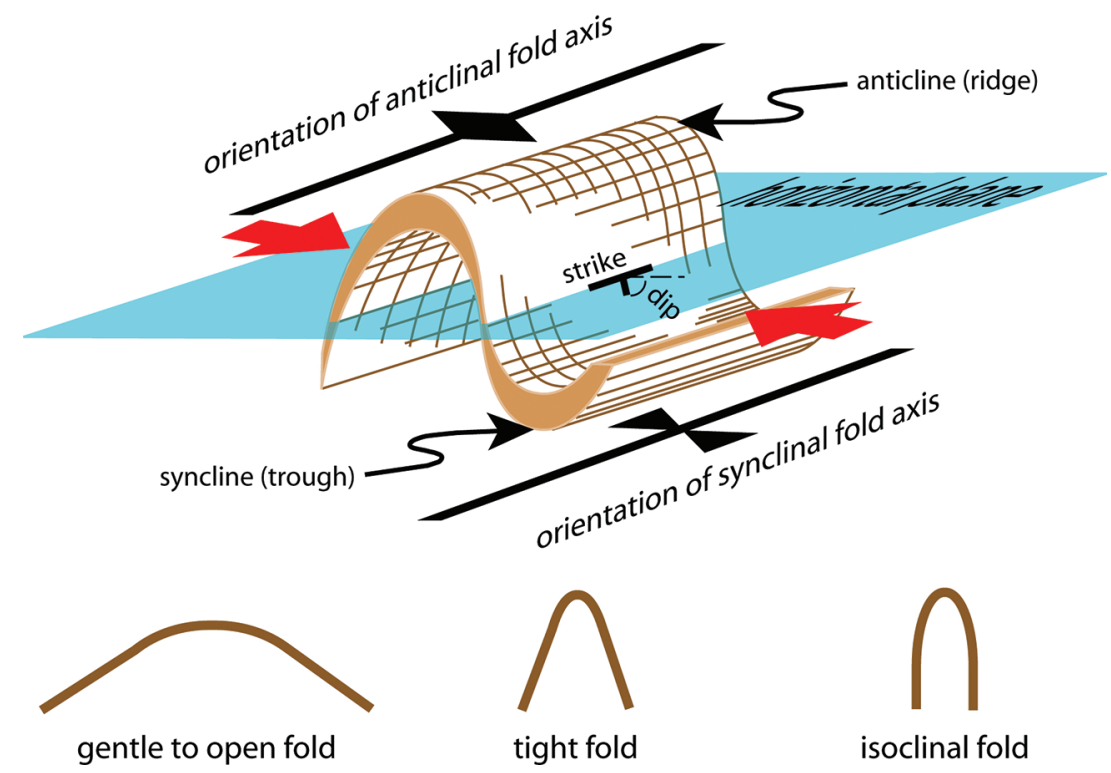

and in the ductile regime to differences in surface temperature, heat flow, crustal thickness, crustal and mantle rheologies, strain rates, and the state of hydration of the crust and mantle. This generality underscores the recognition that any study of comparative planetary tectonics must take these factors into account, but likewise that differences in the manifestations of tectonic deformation may serve to illuminate the influence of such parameters on the lithospheres of the rocky planets. Of course, the lithospheric strength envelopes in Fig. 2 are shown for present conditions, and tectonic landforms formed earlier in geological history must be put into the context of the lithospheric structure at the time of their formation (e.g., when higher heat flux would make for thinner lithosphere than today). This temporal aspect is key for understanding how modern lithospheric structures and their associated tectonic processes serve as analogues to ancient lithospheric structures and their governing processes.

Even so, commonalities in lithospheric structure can be drawn between pairs of planets and among all rocky planets. For all rocky planets, at least the uppermost portions of their crust and for Mercury, Earth, and Mars also the lower portions of the crust and perhaps even the uppermost mantle - behave in a brittle manner, such that brittle processes involving jointing and faulting would dominate the surface expressions of tectonic landforms. Furthermore, the compiled solutions to strength envelopes suggest that both Mars and Mercury may have substantially thicker modern lithospheres (and thicker brittle portions) than Earth or Venus, implying that recent faulting and seismicity are generally expected to extend to greater depths (aside from seismicity associated with lithospheric subduction on Earth). In contrast, the thinner lithospheres (and thinner brittle portions) on Earth and Venus allow for a wider diversity of long- and mediumwavelength tectonic phenomena, such as flexural responses to lithospheric loads, and perhaps the great horizontal mobility of plates on Earth (and, to a lesser extent, lithospheric blocks on Venus).

\section{Structures of interest}

The study of structural geology and tectonics in the planetary sciences relies on remotely sensed images, topography, and other data acquired from flybys or from orbit, as well as more spatially limited in situ data from landers or rovers. Interpretation of struc- tures is based on recognition of geomorphologic characteristics, such as positive- or negative-relief landforms or diagnostic map patterns. In this section, we summarize geometric properties of important structures and discuss how they are observed, mapped, and interpreted.

\section{Folds}

Folds are formed when initially homoclinal structures structures with constant attitude - are distorted, or folded, into curved structures (Fig. 3). Tectonic folding occurs both in the brittle and ductile regimes and is thus accommodated by brittle and ductile deformation mechanisms. In the brittle regime, folding is accommodated by the flexure of geologic units that produces and utilizes fractures of multiple orientations. In the ductile regime, folding is accommodated by plastic deformation, i.e., flow, of the rock volume. There are many details on geometry, mechanisms, and processes involved in folding, and they depend on a wide range of factors, including the orientation of stresses with respect to, and the rheological properties of, the folded geologic units. Here we focus on those terms and characteristics of folds that are important for the recognition and description of folds on planetary surfaces, particularly where in situ and (or) cross-sectional observations are not available.

A fold consists of a hinge connecting two limbs. The hinge is a linear structure that coincides with the axis along which maximum curvature occurs, whereas the limbs tend to be planar structures. If the hinge line is not curved, it is also commonly referred to as the fold axis. Hinges do not necessarily coincide with fold crests. Limbs dipping toward the hinge form troughs, or synforms, and limbs dipping away the hinge form ridges, or antiforms; when the facing direction, i.e., upward direction at the time of folding, is known, synforms and antiforms are referred to as synclines and anticlines, respectively (Fig. 3). Folds with only one limb are generally referred to as monoclines. On structural maps, ridges are indicated with lines following the hinge that have arrows or triangles pointing away from the hinge, whereas troughs are mapped with lines following the hinge that have arrows or triangles pointing toward the hinge (Fig. 3). Monoclines are shown with lines following the hinge that have one arrow indicating the dip direction of the limb. 
Fig. 4. Annotated block diagrams of fault types showing the offsets (red double arrows), fault planes (white planes), possible fault-related folding, and direction of tectonic transport (red bold arrows) for individual fault blocks, as well as map symbology. (A) Normal fault,

(B) high-angle thrust fault, (C) thrust fault, and (D) strike-slip fault. [Color online.]

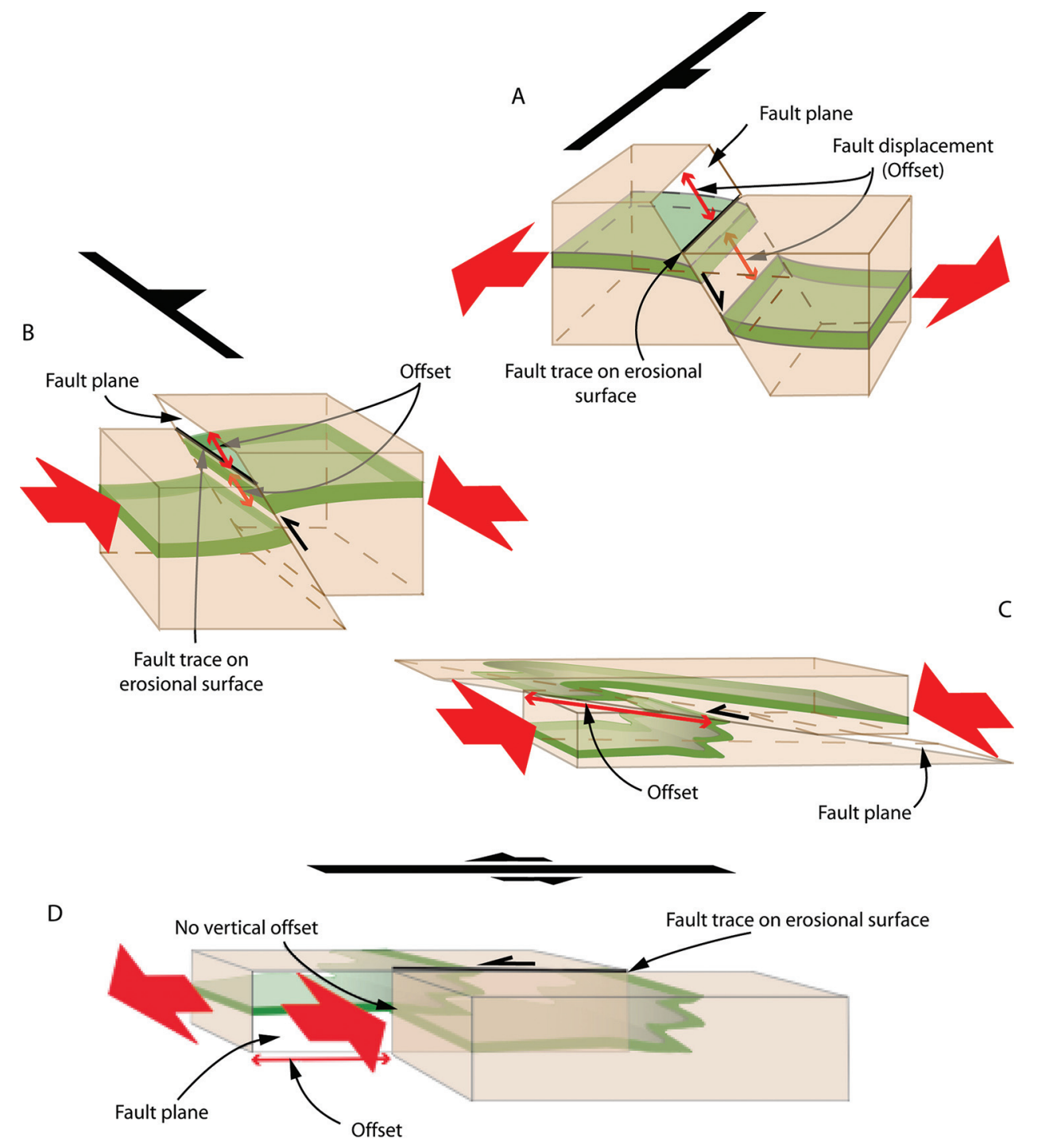

The degree of folding, i.e., the amount of distortion or curvature of the folded rock volume, is generally categorized in terms of the fold tightness. Limbs at angles to one another between $180^{\circ}$ and $70^{\circ}$ make gentle to open folds, whereas interlimb angles smaller than $70^{\circ}$ produce tight folds. Folds with limbs that are nearly parallel are referred to as isoclinal folds (Fig. 3).

All the folds shown in Fig. 3 are symmetric: that is, the limbs have similar dip but antithetic (i.e., opposite) dip directions. In contrast, asymmetric folds have limbs that show substantial differences in dip angles and with dip directions antithetic or even synthetic to one another. Fold asymmetry leads to inclined or overturned folds that have an upper and lower limb and an inclined axial plane. The direction of fold overturning has been referred to as vergence since Stille's suggestion in 1930 (Stille 1930). Fold vergence is an indication of the direction of tectonic transport.

Folds are best studied in cross sections perpendicular to their hinge lines, which can be difficult to discern on Mercury, Venus, or even Mars, where a fold has yet to be discovered in rover images. On planetary surfaces for which our understanding of tectonic structures involving folding is mostly informed by image and topographic data sets, careful inspection of morphologic sig- natures of folds and their interpretation as ridges and troughs form the primary means by which they are characterized. Although folds develop in a variety of tectonic settings, they are perhaps most easily recognized on planetary surfaces when they form in association with faults to form fault-related folds, historically termed "faultfolds" (Holmes 1876) or "Bruchfalten" (Suess 1885), which include fault propagation folds, displacement-gradient folds, and drag folds (see next section).

\section{Faults}

Faults are planar structural discontinuities along which shear displacement is localized (Schultz and Fossen 2008). In the brittle regime, displacement is accommodated by frictional sliding, whereas deformation along faults that penetrate into the ductile regime is accommodated by plastic deformational micromechanisms that form shear zones and mylonites (e.g., Cowie et al. 2013). The amount of shear displacement, or offset (Fig. 4), is usually the result of multiple faulting events along the fault surface. The direction of slip with respect to the orientation of the fault surface gives rise to a kinematic classification of faults into two endmember models: dip-slip faults (Figs. 4A-4C) and strike-slip faults (Fig. 4D). 
Dip-slip faults are faults with generally inclined fault planes, where the offset occurs along the axis of the dip of the fault plane. If the rock volume above the fault plane (the hanging wall) moves downward with respect to the rock volume beneath the fault plane (the footwall), the fault is referred to as a normal fault (Fig. 4A); structures showing upward displacements of the hanging wall relative to the footwall are referred to as thrust faults (Figs. 4B-4C). Strike-slip faults are those faults for which offsets are horizontal, in the direction of the strike of the fault (Fig. 4D); on any inclined plane, this lateral displacement can occur with a left-lateral or right-lateral sense of shear, termed sinistral and dextral, respectively. In contrast to these end-members, most faulting is observed to display a combination of along-dip and alongstrike slip (i.e., oblique slip) on surfaces that range from nearhorizontal to vertical (Angelier 1994).

Frictional properties of rock masses show that certain fracture planes are always oriented more favorably for frictional sliding than others when subject to tectonic stresses (e.g., Zoback 2007). This situation leads to characteristic fault orientations relative to the major tectonic stress axes (i.e., the principal stresses). Basalts, which make up much of the brittle portion of the terrestrial oceanic lithosphere (Fig. 2), show optimal orientations for frictional sliding at angles acute to the maximum principal stress (Jaeger et al. 2007), so normal faults are predicted (and are widely found) to form with dip angles (as measured from horizontal) of $\sim 60^{\circ}$, thrust faults with dip angles of $\sim 30^{\circ}$, and strike-slip faults with vertical dip angles. Although assumptions for typical frictional properties of basaltic rock masses and resultant fault orientations are good first-order approximations for planetary fault analogues, many exceptions, such as low-angle normal faults with dip angles less than $\sim 45^{\circ}$ (Wernicke 1995), and high-angle thrust faults with dip angles exceeding $45^{\circ}$ (e.g., Sibson 1990; Fig. 4C), are observed on Earth.

Many maps published in the planetary science literature show faults as plain lines without using specific symbols for fault types. However, fault symbols and map notations of linear structures in general contain information on strike, length, and segmentation and, when used properly, should also provide information on the dip direction and direction of tectonic transport. Generally, faults should be mapped using lines with thicknesses greater than those for geologic contacts. Normal faults are usually further specified with solid rectangular boxes on the hanging wall (i.e., downthrown) side of the mapped line (Fig. 4A), but other notations such as hachures or, mainly in the United States, ball and bar symbols, are used, too. Thrust faults are indicated with a triangular symbol on the hanging wall (i.e., upthrown) side of the mapped line (Fig. 4B). Strike-slip faults are generally indicated by half arrows that show the direction of relative movement of the blocks (Fig. 4D). Oblique faults are indicated on maps by decomposition of the slip vector into their dip-slip and strike-slip components and using both appropriate dip-slip and strike-slip symbols to indicate the overall kinematics of this type of fault.

\section{Representations of faults and folds on planetary surfaces}

\section{A guide to recognizing fault-related landforms on planetary surfaces}

In contrast to Earth, there has been no major erosional leveling on Mercury, Venus, or Mars, and so faulting is manifest, and can be recognized, by distinct landforms. Figure 5 displays examples of landforms associated with each of the fault types from Mars, but similar landforms are reported from Mercury (Byrne et al. 2018) and Venus (Solomon et al. 1992). Recognition of fault-related landforms relies on knowledge of relief and thus can be challenging where topographic information is not available or of insufficient resolution. In such cases, recognition of landforms relies on interpretation of shadows and detection of diagnostic map patterns of faults on image data sets.
Planetary normal faults, like those on Earth, often form grabens; in the absence of substantial erosion and (or) burial by sedimentary infill, they are apparent on a planetary surface as linear topographic lows (troughs) formed by the down-dropping of a crustal block along two steeply dipping, bounding, antithetic normal faults (Fig. 5A). In addition to this distinctive topographic expression, interactions between overlapping normal fault segments lead to relay ramps, which are diagnostic of normal faulting. On large normal faults, isostatic adjustments and mechanical responses of the rock volume surrounding the faults produce gentle synclinal flexures in the footwall (termed footwall uplift) and a gentle anticlinal flexure in the hanging wall, forming footwall synclines and hanging wall (or rollover) anticlines, respectively (see Buck 1988), which may be observable only in topographic data acquired at high spatial and vertical resolution. Drag folding may also be observed where faults are exposed in cross section, such as in outcrops on Earth, and can show gentle anticlines in the footwall and gentle synclines in the hanging wall (Fig. 4A).

Planetary thrust faults produce characteristic positive-relief landforms, often generically termed "lobate scarps", "high-relief ridges", or "wrinkle ridges" (see discussion in next section). The corresponding landforms produce symmetric or asymmetric ridges. Surface-breaking thrust faults (Fig. 5B) generally produce asymmetric landforms, with one steep-sloped cliff facing the direction of tectonic transport and a gentler slope dipping in the same direction as the underlying fault plane (e.g., Schultz 2000; Schultz et al. 2010). Blind thrust faults have landforms with either asymmetric or symmetric ridges with crowning folds. These landforms are widely interpreted as fault-related folds that formed as a consequence of accumulation and variations in slip along the fault. The folding geometry in the hanging walls of thrust faults is highly variable, depending on the structural style of faulting, but folds may be tight and can involve overturning of the steeper of the two-fold limbs (Fig. 4C). In some cases, thrust faulting might also be accommodated without major folding, such that their corresponding landforms form simply from the tilt and translation of the hanging wall rock mass above that of the footwall.

Strike-slip faults have very subtle expressions on planetary surfaces and therefore are among the most difficult structures to detect without those structural tools available to a geologist on Earth. For small offsets or a lack of pronounced offset markers, such faults may be recognized only from very small topographic differences between the fault blocks, as is the case for most of the example shown in Fig. 5C. However, fault segmentation or sudden changes (bends) in fault strike produce negative-relief pull-apart basins (Fig. 6A) or positive-relief push-up ridges (Fig. 6B), and those landforms can facilitate the recognition and interpretation of strike-slip structures.

\section{Characterizing shortening structures in planetary tectonics}

The formation of fault-related landforms involves folding, and thus interpretation and proper mapping of such landforms should consider both faults and folds. Thrust faulting, in particular, produces a wide variety of fold shapes and patterns. For this reason, thrust-fault-related landforms have generally not been described as such on the rocky planets but instead have been categorized by the terms mentioned above (i.e., wrinkle ridges, high-relief ridges, or lobate scarps) on Mercury (e.g., Strom et al. 1975; Dzurisin 1978), Venus (e.g., Kreslavsky and Basilevsky 1998; Bilotti and Suppe 1999), and Mars (e.g., Watters 1993; Golombek et al. 2001; Mueller and Golombek 2004; Mueller et al. 2014).

First observed and described on the Moon (e.g., Bryan 1973; Masursky et al. 1978), the landforms termed "wrinkle ridges" are manifest as broad, steep-sided but low-relief arches that are mostly symmetric in cross section and may have crenulated crests. A characteristic property of wrinkle ridges is the substantial morphological variation along strike, with changes to width, height, and landform symmetry often observed (see summary by 
Fig. 5. Examples of landforms on Mars formed by different types of faulting, with corresponding map interpretations. (A) Segmented normal faults that are part of Claritas Fossae form a series of grabens. (B) Segmented thrust faults form the $540 \mathrm{~km}$ long and topographically pronounced Bosporos Rupes thrust-fault-related landform. Black arrows point to fault splays. (C) Subtle topographic expression of a right-lateral strike-slip fault (Okubo and Schultz 2006), showing examples of push-up ridges and small pull-apart basins (shown in Fig. 6 in greater detail). [Color online.]
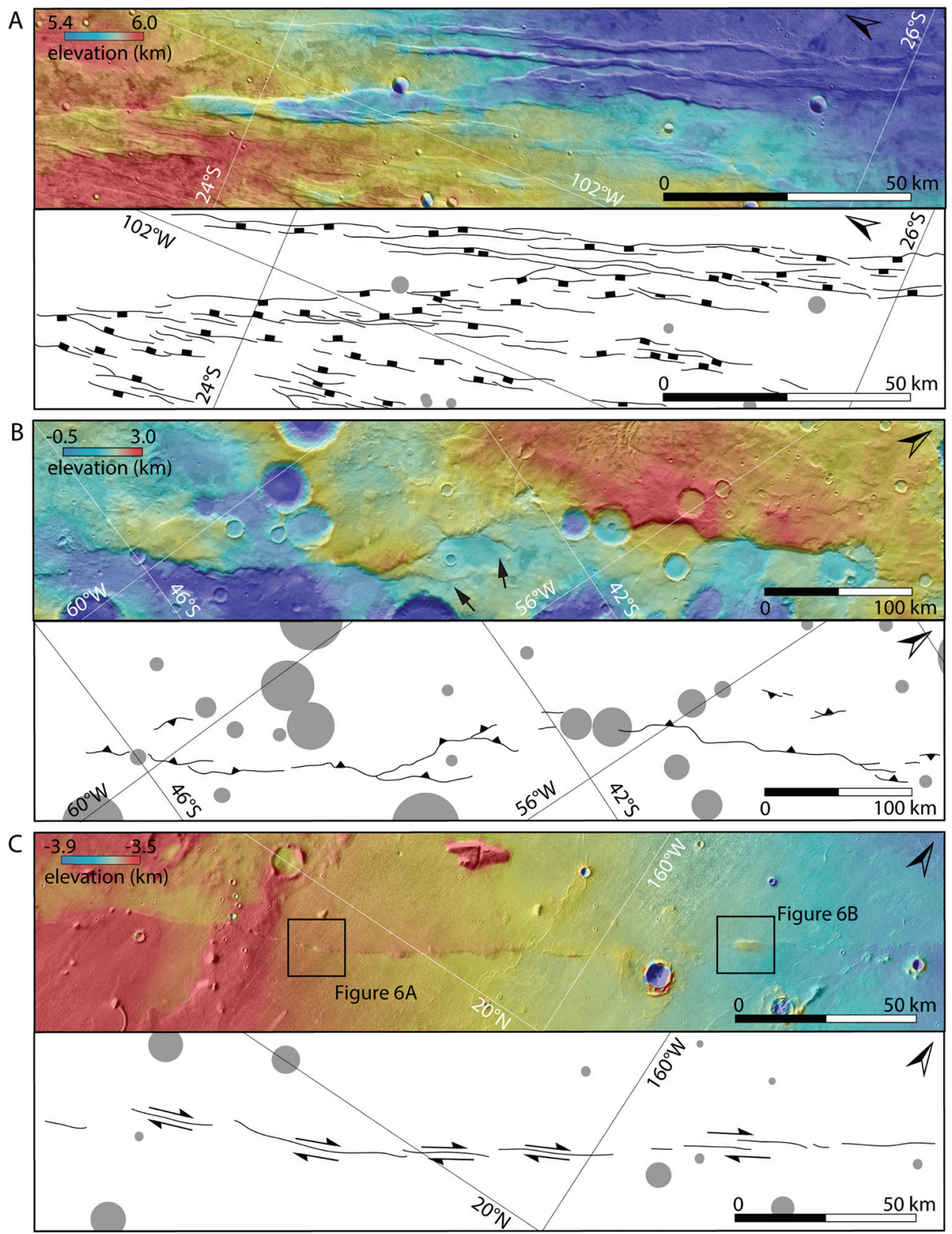

Schultz (2000)). These structures are commonly found on all rocky planets (e.g., Bryan 1973; Dzurisin 1978; Kreslavsky and Basilevsky 1998; Mueller and Golombek 2004). As noted by Byrne et al. (2018), landforms proposed as analogues to wrinkle ridges have been described at numerous sites on Earth, including Algeria, Australia, and the United States (e.g., Plescia and Golombek 1986; Watters 1989, 1988), and in each case they feature distortion (including folding) of the hanging wall of thrust faults. No consensus on the orientation and depth of the underlying faults and the kinematics of fault-related folding of wrinkle ridges has been reached in the planetary tectonics community (e.g., Plescia and Golombek 1986; Watters 1988, 1991; Golombek et al. 1991; Plescia 1991, 1993; Schultz and Tanaka 1994; Zuber 1995; Schultz 2000; Mueller and Golombek 2004). The steep escarpments that bound wrinkle ridges can themselves be regarded as monoclines, such that where they occur, two opposite-facing ridge-bounding scarps are essentially paired monoclines. Accordingly, where wrinkle ridges have steep sides, they, too, can be said to have vergence (cf. Byrne et al. 2018).

As suggested by their name, high-relief ridges tend to show greater relief than wrinkle ridges, but they have also been noted to be generally symmetric in cross section (Watters et al. 2001). The term has been applied to a set of positive-relief landforms on Mercury but has rarely been applied to any other planetary body. Although considerable along-strike changes in size and shape are less commonly seen for that category of landform, some variations in width, height, or vergence occur (Watters et al. 2001). 
Fig. 6. Mars Reconnaissance Orbiter Context Camera (CTX) images of strike-slip fault landforms (from fault in Fig. 5C). (A) Right bend in the strike of the right-lateral fault caused a pull-apart basin to form. (B) A left step between two en echelon right-lateral fault segments produced a push-up ridge.

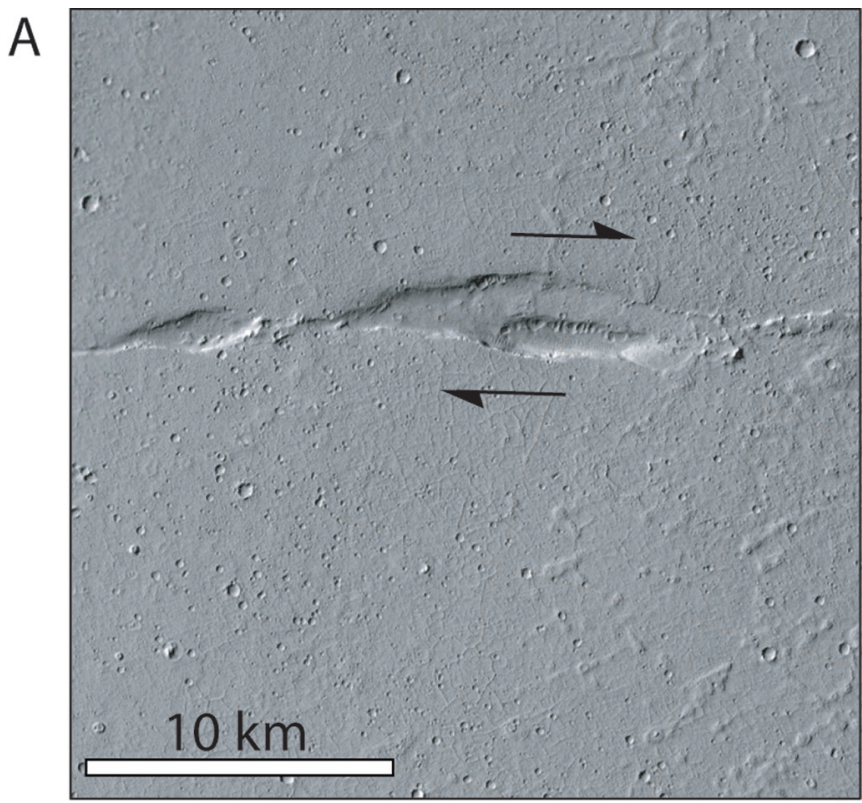

B

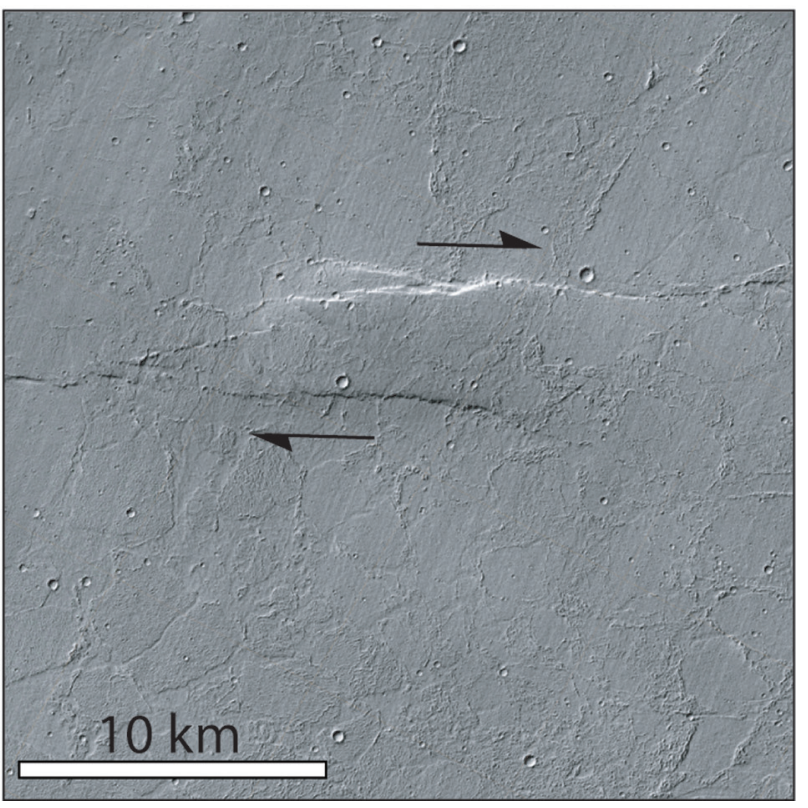

In contrast to the mostly symmetrical cross sections of wrinkle and high-relief ridges, lobate scarps are commonly described as highly asymmetric in transverse view, with steep slopes on one side and gentle backslopes on the other. In map view, they have relatively steep and long escarpments that typically trace a broadly lobate fault surface break, although some lobate scarps, such as Beagle Rupes on Mercury, have strongly arcuate forms (Rothery and Massironi 2010). Many such structures show smaller, subordinate scarps along their leading edges (Fig. 5B) that have previously been described using generic terms (Watters 1988) as second- and third-order ridges, but Klimczak et al. (2018) applied geologic nomenclature to describe them as minor thrust faults and fault splays.
As upthrust volumes of rock, then, lobate scarps are the folded or tilted portions of the rock mass in the hanging walls atop thrust faults. With fault nomenclature, many lobate scarps are therefore fault-propagation or fault-bend folds, which together may be classed as "fault displacement-gradient folds" (Wickham 1995). On the basis of the shape of this landform alone, lobate scarps are asymmetric hanging-wall anticlines or monoclines. The folding and tilting of the rock mass in the hanging wall of the thrust fault is accommodated by brittle deformation as outer-arc extension (Figs. 7A, 7B) along the fold hinges, manifest as joints and narrow grabens along the crests of scarps (Fig. 7). That such structures are reported for the Moon (Watters and Nimmo 2010), Mercury (Byrne et al. 2018; Fig. 7C), and Mars (Mueller and Golombek 2004) shows that this mechanism commonly accompanies the growth of these landforms, which, in turn, implies that hanging walls of planetary thrust faults are highly fractured. Such deformation may lead to differences in the mechanical properties of the rock volumes between the hanging wall and footwall, and these differences may need to be considered when attempting to derive model age dates for thrust faults from the areal density of proximal impact craters. The asymmetry of lobate scarps likely reflects the vergence of the hanging-wall anticline, which in turn gives the direction of tectonic transport along the underlying fault (e.g., Byrne et al. 2014).

Despite the large number of studies characterizing the morphology and comparing positive-relief landforms on other rocky bodies to shortening structures on Earth, the generic terms "lobate scarp" or "wrinkle ridge", which lack any hypothetical interpretation, persist in the planetary tectonics literature. Furthermore, the morphology of shortening landforms on the rocky planets is sufficiently variable that no single set of quantitative morphological criteria exists by which such landforms can be grouped into one of these end-member cases. Many examples of lobate scarps with morphological characteristics matching those described for wrinkle ridges, and vice versa, or where one landform transitions into another, show that this categorization is not helpful for understanding the fault and fold architectures and the tectonic processes involved in forming them. Byrne et al. (2018) presented an extensive list of structures on Mercury that show sufficient morphologic complexities that the classification into one distinct group breaks down, but such lists are not limited to Mercury, and examples abound on the Moon, Venus, Mars, and, of course, Earth. In fact, that shortening structures show a wide variation of fold geometry within the same structure has long been recognized on Earth. Reconstruction of fold geometry preserved in Cretaceous strata along the Elk Mountains (Colorado, USA), for instance, was carried out by Holmes as early as 1874 (Holmes 1876; Suess 1885). A series of profiles across the Elk Mountains (Fig. 8) highlights the variability of fold shapes along a single structure, where anticlinal geometries range from gentle and broad to tight and overturned in a single system.

A classification scheme for shortening structures based only on morphology, and with no interpretation tied to it, cannot capture the broad morphological variations of these landforms and is thus of little help in understanding the tectonic style and geometry of associated faults and folds. Instead, careful structural mapping and descriptions and compilation of observations should be followed by an interpretation that provides testable hypotheses for the shortening landforms in the local, regional, or global geologic context of their planet (e.g., Klimczak et al. 2018). Techniques as simple as the Holmesian method (Holmes 1876) of drawing profiles across shortening landforms (Fig. 8) are eminently useful approaches for facilitating and encouraging scientific interpretation of and debate about extraterrestrial structures.

\section{Patterns of shortening landforms on planetary surfaces}

Map patterns of landforms involving both faults and folds can be indicative or diagnostic of tectonic styles and the subsurface architecture of deformation. This topic is particularly relevant to 
Fig. 7. Formation of crestal grabens atop the hanging wall anticlines of thrust faults. As thrust faults accumulate slip (A), outer-arc extension leads to joints and small grabens (B). An example of crestal grabens on Mercury is shown in an image mosaic (top) and map interpretation (bottom) in (C). [Color online.]
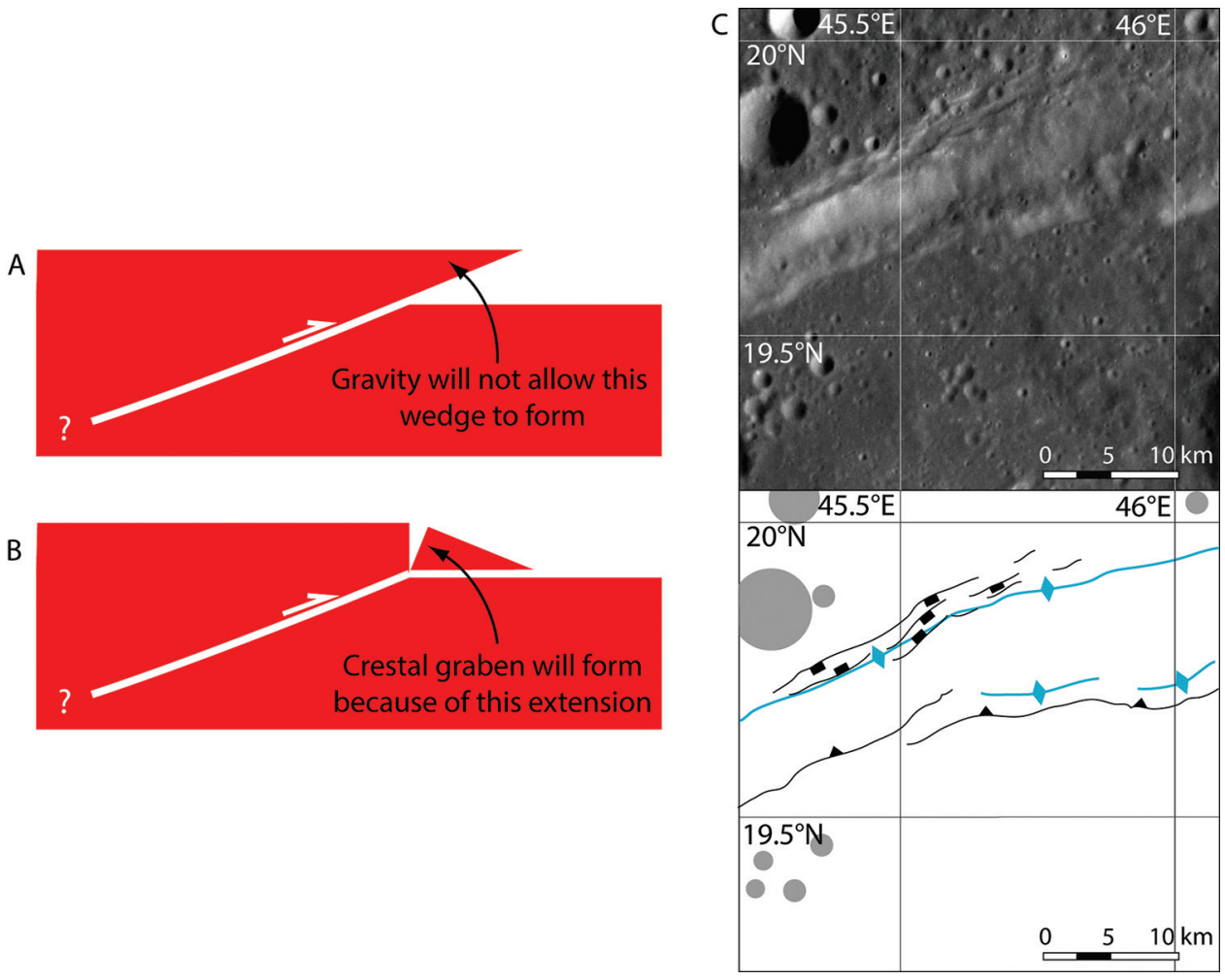

bodies featuring a history of global contraction in response to secular cooling of the interior, including Mercury, Mars, and the Moon. (As an aside, the term "contraction" is used here only for an overall decrease in the volume of a planetary body, whereas the resulting structures, thrust faults and folds, are termed "shortening structures", referring to a decrease in surface length in one horizontal dimension.) Many different patterns of thrust faults and associated folds exist on these rocky bodies (e.g., Byrne et al. 2014, 2015; Klimczak et al. 2018; Crane and Klimczak 2019), but frequently individual features have been described with generic terms, without context to other structures, or without taking terrestrial analogues into consideration. For example, interactions of thrust faults and associated folds with obstacles in the lithosphere or with each other, such as mechanical contrasts between geologic units that can function as detachment horizons, give rise to complex tectonic systems, including syntaxes, virgations, and linking (Fig. 9). Such tectonic structures are reported and described across Earth, but they are largely unknown in the planetary tectonics community, and thus they have not been recognized or described, and the most appropriate terminology has not been applied.

A syntaxis is a convergence of mountain ranges, which on the rocky planets are landforms produced by folds, toward a single point with a sharp deflection of the trend lines of structures on both sides (Fig. 9A). The points themselves are typically obstacles of some kind, such as mechanically strong and coherent volumes of rock, massifs, or the central peaks of impact craters. Prominent examples on Earth are found in the Himalaya (Suess 1885) and include the Hazara and the Assam syntaxes and the Nanga Parbat syntaxes in India.

Virgations are fan-shaped branching of a series of folds (Fig. 9B) that are also frequently accompanied by fractures. Virgations typically occur at the end of folded structures and usually in association with one or more obstacles. If only one end of the folded structure shows a virgation, we refer to such a structure as a simple virgation (as shown in Fig. 9B), but if both ends show the fan-shaped branching of folds, the structure is a double virgation. Double virgations may occur around a single obstacle and so possess free ends, but they may also occur around multiple obstacles and so possess forced ends. Prominent examples on Earth are found in the northern Tien-Shan, Kyrgyzstan, which at its western extent shows a virgation formed by the Chu-Iliiskii, Karatau, and Chatkal'skii ranges, as well as the Gissar-Alai Range, Tajikistan, which shows a virgation on its western termination branching into the Nuratau Range and the ranges of the Tadzhik depression and the Darvaza.

A pattern is referred to as "linking" when a fault system either abuts against another such system or is overridden by another fault and both fault systems were formed by the same tectonic event. This type of fault interaction was first named "Kettung" by von Richthofen (1903, pp. 872 ff.) on the basis of examples in western Pacific magmatic arcs (Fig. 9C). Suess originally called such an interaction "Abschneidung" in the eastern Himalaya, but later, in deference to his deceased friend, started using "Kettung" (Suess 1909a, p. 578; variously rendered into English as "linking" (in Hertha Sollas' translation as edited by her father W.J. Sollas: Suess 1909b, p. 503) or "linkage" (Bucher 1933, p. 81, fig. 18c) and into French as "enchaînement" (Suess 1918, p. 1369)). von Richthofen (1903) recognized two main types: an arc linkage from the side ("flankenständige Bogenkettung"; p. 873) and another arc linkage termed, by von Richthofen, "retroimpounded arc linkage" ("rückgestaute Bogenkettung”; p. 874). Of these, the latter is really a double-sided virgation with free ends, and so we no longer consider it here and confine the term "linkage" to the first kind, best illustrated by the overriding of the Izu-Bonin arc by the Honshu arc at the Fossa Magna. There, one major subduction zone, i.e., a huge thrust fault system, overrides another one. On a smaller scale, in southern England and Wales and in southern Ireland, the 
Fig. 8. Reconstruction of thrust-fault-related folding of Cretaceous strata in the Elk Mountains, Colorado, modified after Suess (1885). (A) Map of lowermost Cretaceous strata at Snow Mass and White Rock, Elk Mountains, Colorado. (B) Series of evenly spaced cross sections drawn across the mountain range highlighting the folding of the strata. This figure is in the public domain.

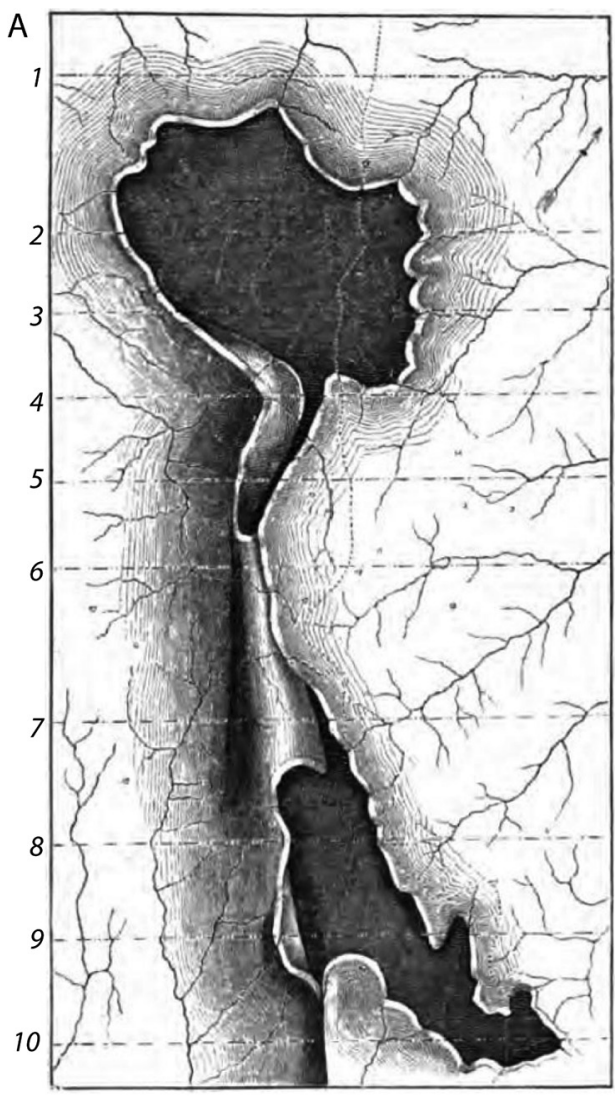

Hercynian thrust front overrides the Caledonian foreland, creating a false linkage, because the structures are of very different ages and belong to different tectonic systems. In another setting, in the Altaids, a large strike-slip fault cuts off the arc fragments of northern Kazakhstan and brings them into contact with the Valerianov-Chatkal unit, forming a real linkage (of the kind Suess called “Abschneidung”, i.e., "cutting off”: Suess 1901, pp. 472-473; see Şengör et al. 2018, fig. 5). If the "linking” fault systems have curvatures in the same sense, they are called "harmonious linkages"; if their curvatures are opposite to each other, they are “disharmonious linkages" (von Richthofen 1903, pp. 872-873). The concept of linkage, as used first by von Richthofen and as used here, is not to be confused with fault linkages that refer to interactions and the coalescence of multiple fault segments into one larger fault, although, in principle, on a much smaller scale they, too, are linkages.

One planetary example for a syntaxis discussed by Byrne et al. (2018) is where an unnamed thrust-fault-related landform cuts through a $\sim 90 \mathrm{~km}$ (diameter) unnamed crater (Fig. 10A). On the crater floor, the folded hanging wall of the thrust fault encounters the central peak of the crater, which forms an impediment. The continued propagation of the unobstructed portions of the fold form a distinct bend in the strike of the shortening structure, forming a textbook example of a syntaxis.

Although not explicitly called out as such in a previous publication (Klimczak et al. 2018), we consider Icaria Rupes on Mars as a candidate double virgation with free ends (see fig. 6 from Klimczak et al. (2018)). The map pattern of this fault system is indicative that the horizontal displacement along this large structure was impeded at the center by a preexisting $30 \mathrm{~km}$ diameter circular mensa, forming a ramp. The unobstructed portions of the

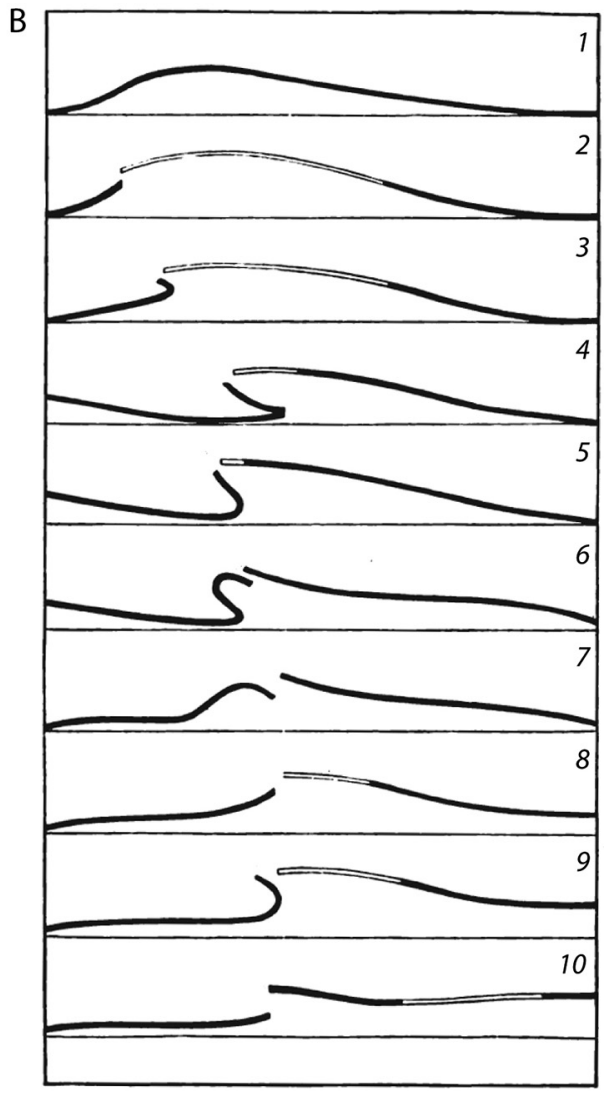

fault form a bend in the map pattern of the shortening structure that is accompanied by folds at its leading edge that branch out on both edges of the structure.

There are no reported examples that specifically describe linkings in the planetary tectonics literature. However, many candidate examples are present in Hesperia Planum, Mars, especially folds and thrust-fault-related landforms associated with, or in the vicinity of, Hesperia and Tyrrhena Dorsa. There, landforms interpreted to be thrust-fault-related folds show systematic patterns in which they terminate at other such landforms at high angles (Fig. 10B). Similar examples of linkings are present in volcanic plains in Borealis Planitia, Mercury.

\section{Joints}

Joints are discrete fractures with opening-mode displacement, i.e., the fracture walls move away from one another (Pollard and Aydin 1988). If fracture walls move perpendicular to the fracture plane, the displacement is purely opening mode and we refer to those structures as tensional joints. If jointing involves a displacement component where fracture walls also move parallel to the fracture plane, we refer to those joints as shear (mixed-mode) joints. Joint sets can be formed by flexure (i.e., folds produced by buckling), which causes tensile stresses in the extrados region of a concentrically folded rock volume (Fig. 11). Longitudinal joints, or b joints, formed by this process show orientations parallel to the fold hinge lines. Joint surfaces forming with orientations normal to the fold axis are referred to as transverse joints, or a-c joints. Both $\mathrm{b}$ and $\mathrm{a}-\mathrm{c}$ joints represent tension joints. Shear joints tend to form diagonally with respect to the fold axis. All of these joints form potential planes of weaknesses that serve as surfaces for tectonic reactivation. 
Fig. 9. Block diagrams and associated map patterns of tectonic systems involving thrust-fault-related folds. (A) Syntaxes, showing convergence of folds toward an obstacle. (B) Fan-shaped branching of folds around an obstacle resulting in a simple virgation. (C) Two possible situations of linking. Note that the same map pattern can arise for two different directions of tectonic transport. [Color online.]
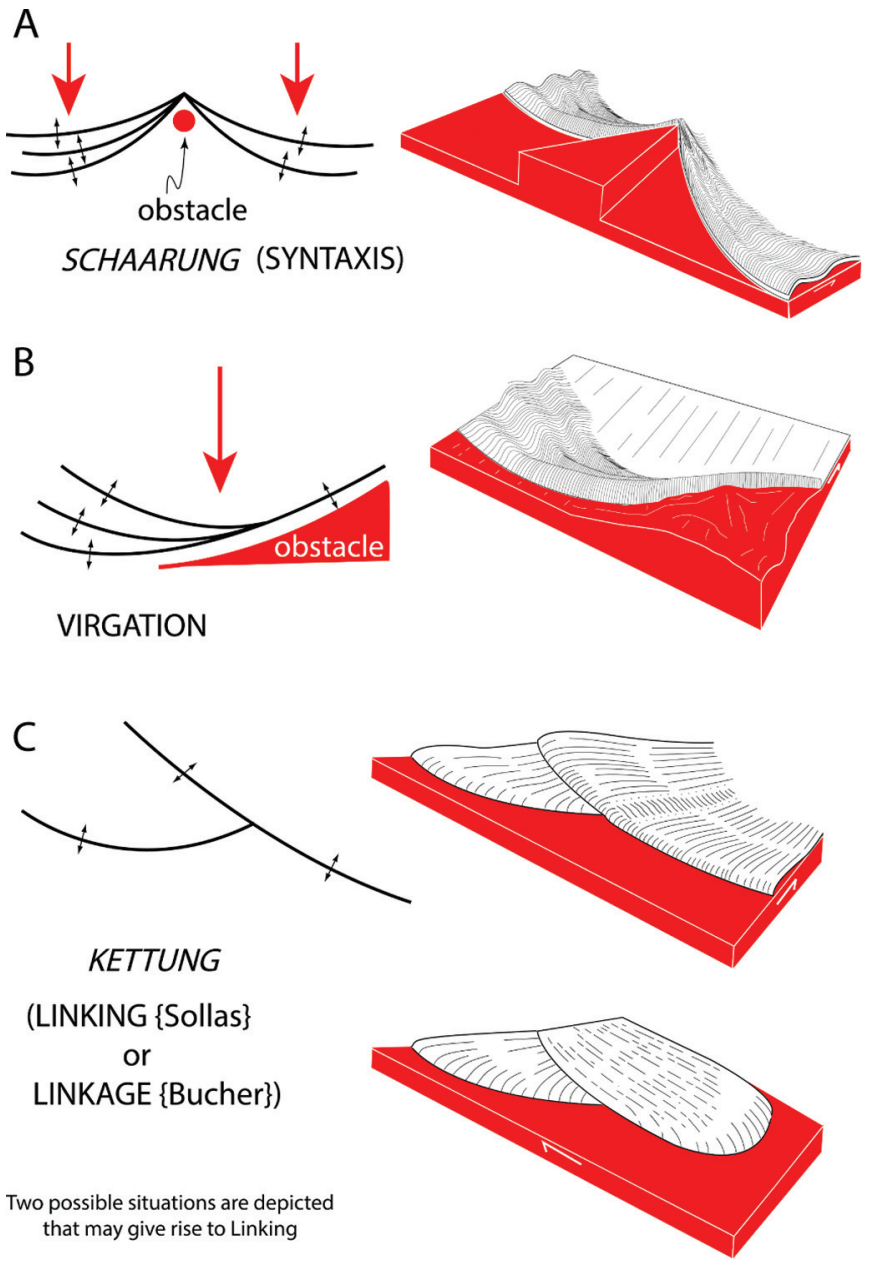

In contrast to the large-scale landforms associated with faulting, opening-mode displacement does not produce landforms of sufficient size to allow easy observation by spacecraft. Therefore, these structures are difficult to study on planetary surfaces and require images from rovers or from orbital imagers capable of resolving planetary surfaces on the centimetre scale, such as those from the High Resolution Imaging Science Experiment (HiRISE) on NASA's Mars Reconnaissance Orbiter. One example includes metre-scale joints forming by subsidence in Candor Chasma on Mars (Okubo 2010). Another example is seen in Fig. 7, where anticlinal flexure and thus outer-arc extension of the rock volume in the hanging wall of thrust faults on Mercury produced joints oriented along the same structural trend as the associated fold and fault, indicating that they represent $b$ joints. That many such crestal b joints ultimately grow large enough to become normal faults and grabens (Fig. 7C) shows that these joints penetrate to sufficient depths that the overburden pressure exceeds the tensile stresses, causing a purely compressive stress state, to facilitate frictional sliding and thus faulting.

On local to regional scales, planetary joints can form from decreases in igneous rock volume during cooling. Such joints are oriented with no preferred orientation and thus frequently produce polygonal patterns of fractures in map view. Prominent examples of cooling joints are preserved in melt sheets that ponded on the floors of fresh complex impact craters, such as those observed on the floors of Hokusai or Degas craters on Mercury (Byrne et al. 2018). Additionally, where impact structures are filled with flood volcanic units, strains associated with the cooling-induced volumetric decreases in rock volume are sufficiently large to form kilometre-scale joints that can transition into grabens (Freed et al. 2012; Klimczak et al. 2012; Blair et al. 2013). In smaller flooded impact structures, these joints and grabens show no preferred structural trend and form polygonal patterns. However, in impact basins, the structural trends of grabens are preferentially radial or concentric to the center of the impact structure (Byrne et al. 2018).

Tension joints have also been postulated to form globally on Mercury as a result of tidal despinning (Klimczak et al. 2015), the slowing of an initially fast spin rate to the planet's current 3:2 spinorbit resonance. Tidal despinning could have occurred early in Mercury's geologic history, so that the resulting joints may not have been preserved in the geologic record, but this process is often invoked to have occurred late and to have overlapped with global contraction (e.g., Pechmann and Melosh 1979). The tectonics of despinning operating in isolation involves relaxation of an equatorial bulge and flattening at the poles, both effects producing substantial tensile stresses and perhaps shear stresses that would produce shear joints in a manner that both Vening Meinesz (1947) and Sonder $(1947,1956)$ proposed had been important for Earth. Whereas global patterns from despinning on Earth, if they ever existed, have long been erased or overprinted, the framework is relevant for one-plate planets that likely despun, such as Mercury. However, the only effective way to evaluate the type and orientation of structures that would have formed from such processes is by rock-mechanical assessment (Klimczak et al. 2015). Such analysis predicts a pattern of joints with east-west preferred orientations at equatorial and mid-latitudes and random orientations at the poles. In contrast, if tidal despinning temporally overlapped with global contraction, no joints would form, and instead north-south-oriented thrust faults are predicted to have developed at equatorial and mid-latitudes; faults would have random to east-west orientations at the poles (Klimczak et al. 2015). Similar outcomes can be invoked for the Moon, as the same processes have been proposed to have operated there.

\section{Karst}

Although the formation of karst is not primarily a tectonic phenomenon, karst processes are frequently structurally controlled or produce collapse structures that can easily be confused with tectonic structures, and thus this topic is of some relevance for planetary structural geology. Karst refers to a plateau made up mainly of Triassic and Jurassic neritic limestones north and east of Trieste in the historical region of Carniola, today in Slovenia. It has given its name since the middle of the nineteenth century to a peculiar kind of landscape formed by the dissolution of soluble rock either fully exposed on the surface or reached by various pathways into the subsurface, forming a pock-marked topography of various solution features (lapiès, dolinas, uvalas, poljes, alvars, vertical pits called "obruk" in Anatolia, blind valleys, and canyons) and underground drainage systems that form caves of a bewildering variety of shapes and natural bridges formed by collapsing caves. Most caves ultimately collapse to form distinct landforms. These structures collectively form the so-called karst topography (or "karst regions": Cvijić 1893, 1960; Fig. 12A). With ongoing dissolution and an evolving karst landscape, a series of dolinas, small (diameters ranging from several to hundreds of metres), equant, and shallow, usually cauldron-shaped depressions, may coalesce into larger compound structures, referred to as "uvalas" (Fig. 12B). Very large, flat-floored depressions, frequently elongate and aligned with structural trends along which the dissolution preferentially occurred, are referred to as "poljes" (Cvijić 1893, 1901; Fig. 12). Mature karst systems are characterized by degradation of collapse structures manifest as widened and 
Fig. 10. Examples of thrust-fault-related patterns of folds on Mercury and Mars presented as image mosaics (top) and map interpretations (bottom). (A) Syntaxis on Mercury, formed where the central peak (CP) posed an obstacle to a thrust-fault-related landform. (B) Linking in Hesperia Planum on Mars. Note how thrust faults abut against other thrust faults. [Color online.]
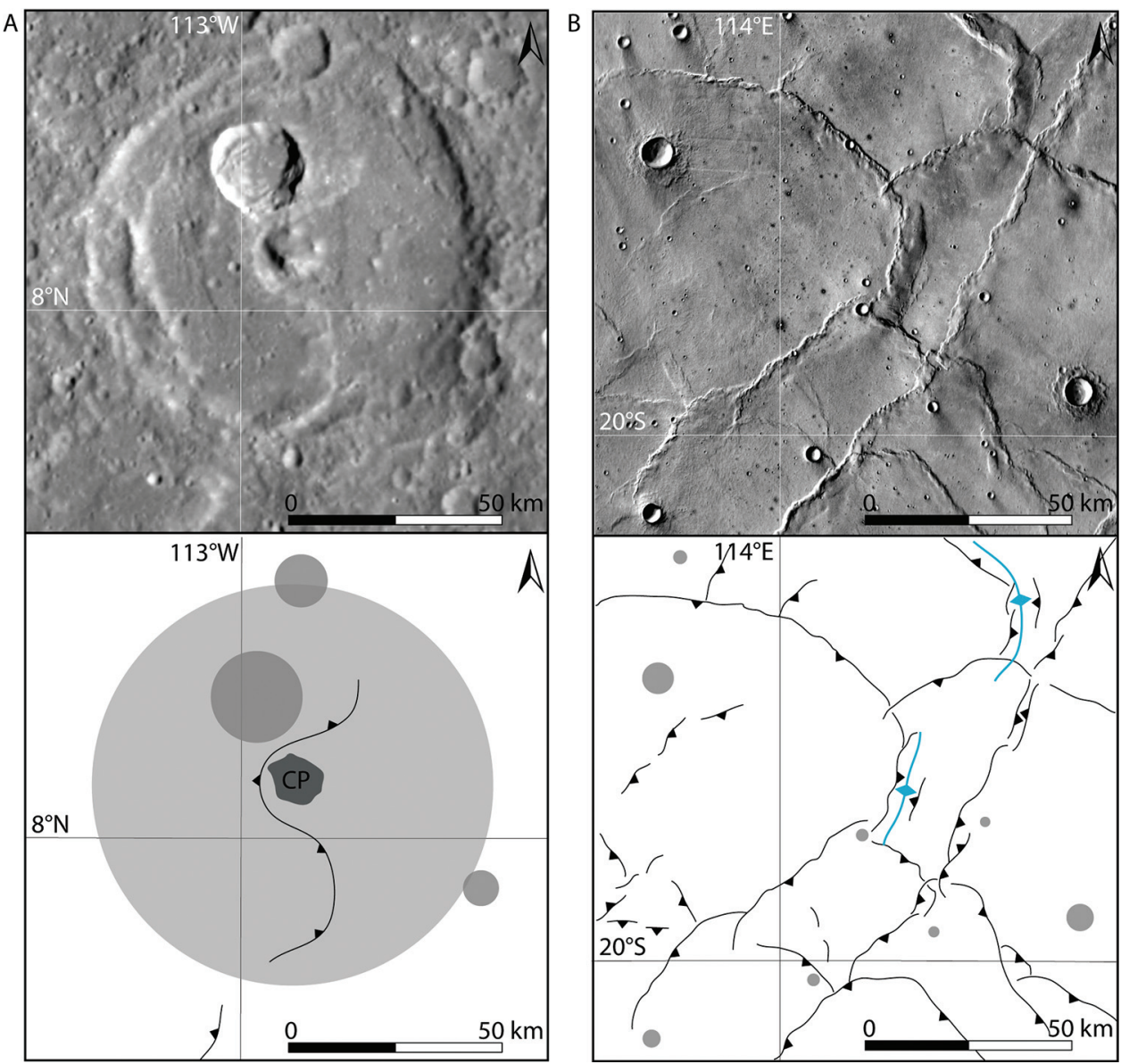

Fig. 11. Joint sets associated with folds. Joints with orientations parallel with the fold hinge lines are longitudinal or b joints (purple). Joints normal to the fold axis are transverse or a-c joints (orange), and joints diagonal to the orientation of the fold are shear joints (green). [Color online.]

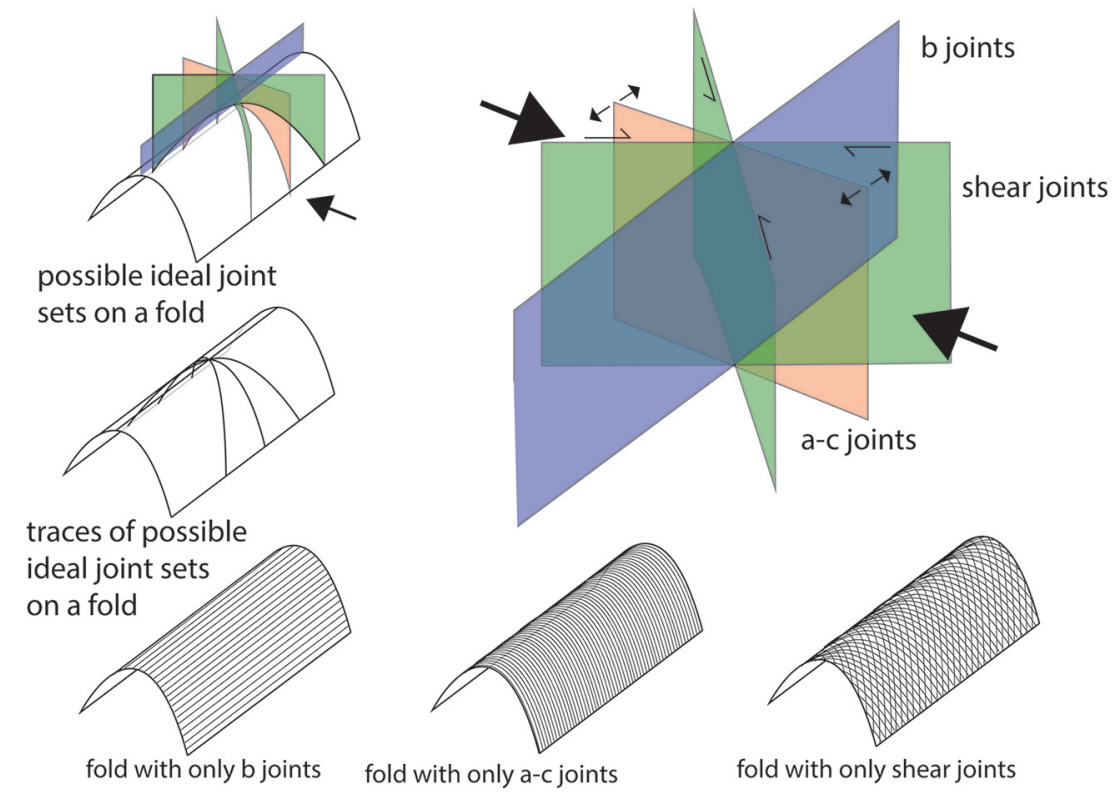


Fig. 12. Evolution of karst topography illustrated by Lobeck (1939, p. 132) on the basis of the extensive karst research carried out by Cvijić (1960) and presented in a Davisian evolutionary model. (A) Early youth: poljes and dolines form along structural weaknesses that were utilized as hydrological pathways. Structural weaknesses may include joints and faults of all sizes. (B) Late youth: continued collapse forms additional dolines that coalesce to form uvalas. (C) Maturity: continuous degradation of collapse structures leads to widening and infill of depressions. (D) Old age: erosional leveling erases all but the largest collapse structures. This figure is in the public domain.
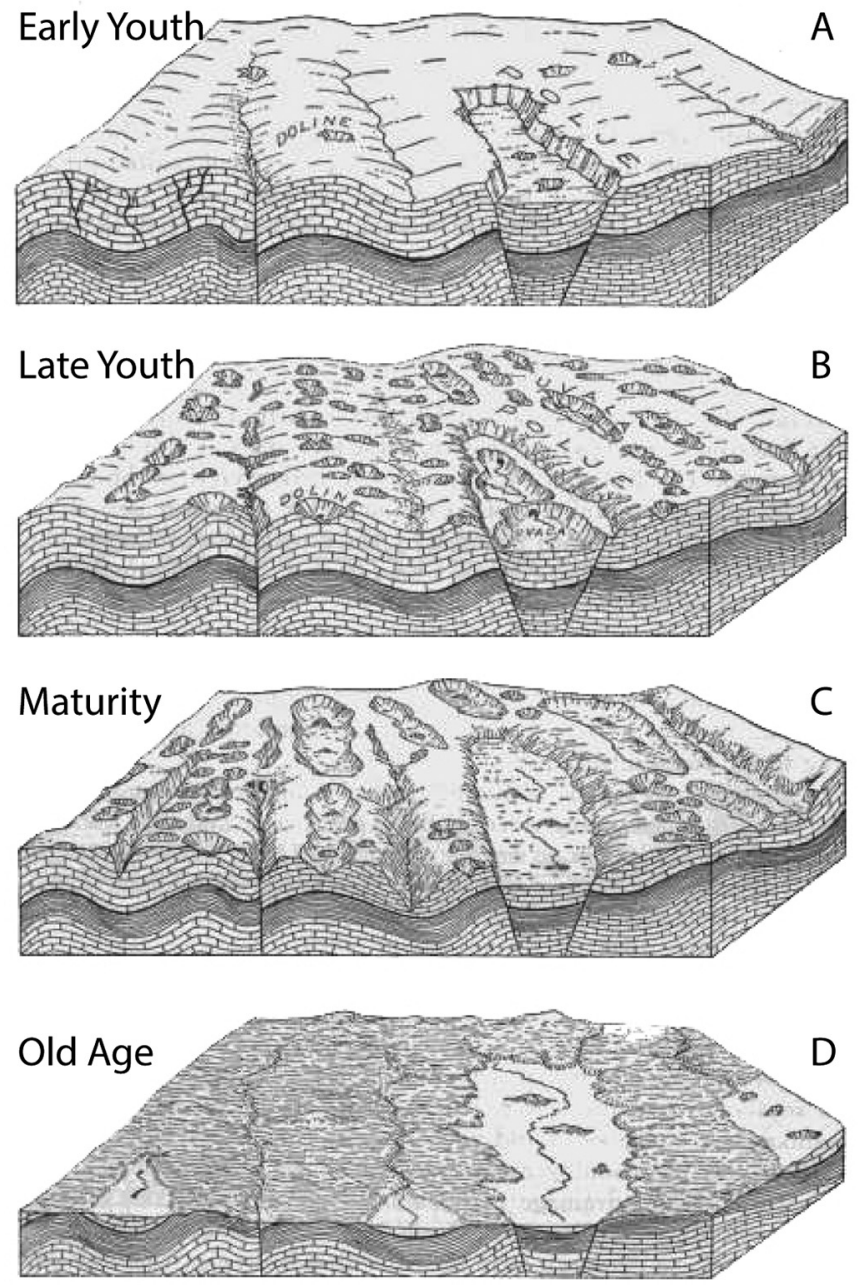

filled depressions (Fig. 12C), with erosional leveling ultimately leaving behind only subdued topography marked by wide, flat valleys with little topographic difference from the surrounding terrain (Fig. 12D).

The great Serbian geographer Jovan Cvijić studied the karst forms in eastern Serbia for his Ph.D. thesis (Cvijić 1893), the first general synthesis of karst topography, and he later extended his studies to the karst on the Balkan Peninsula and showed that the entire Dinaric mountain range exhibited a magnificent development of karst topography (Cvijić 1893, 1900, 1901, 1960). His work accounts for the fact that most internationally used terms for karst landforms, including doline, uvala, and polje, are derived from the Serbian language. For an excellent recent reference to karst phenomena and features, see Ford and Williams (2007).

Although traditionally described for landscapes produced by dissolution of soluble rock involving liquid water, karst landscapes may also be produced by processes that do not require a steady source of liquid water as solvent, or can form in rock types that are not easily soluble. Such karstic structures are referred to as examples of pseudokarst. One such pseudokarst example is thermokarst, which forms in ice-rich permafrost (see Czudek and Demek 1970). Thermokarst produces distinct landforms that may closely resemble ordinary, solution-related, karstic structures when ice is melted suddenly, or when large pockets of gasses stored in the subsurface are suddenly released into the atmosphere. Such types of karst are relevant planetary analogues that may be formed in geologic settings where the lack of sustained sources of liquid water, and their interactions with soluble rock, precludes the formation of karst in the traditional sense. Thermokarst in particular has been invoked to explain peculiar geomorphology associated with hollows on Mercury (Kargel 2013), as well as multiple landscapes on Mars (Baioni et al. 2009, 2017), including Valles Marineris (see below).

\section{Applications to Mercury}

Mercury is the smallest planet in our solar system, and it is closest to the sun. Therefore, it has the highest surface-area-tovolume ratio of the planets and is in tidal resonance with our local star, which both have had major effects on its thermal and rotational evolution and thus the tectonics found there. As mentioned above, Mercury's tectonics have been dominated by global contraction, which accounts for the formation of the many shortening structures observable on the surface of this planet (e.g., Byrne et al. 2014). Although progress has been made on the amount (Byrne et al. 2014), timing (Banks et al. 2015; Crane and Klimczak 2017), and rate (Crane and Klimczak 2017) of global contraction, no clear picture exists on the early phase of global contraction and how it ties in with Mercury's early geologic evolution. However, the hypothesis of a contracting Earth as first invoked by Élie de Beaumont (1829) and Dana (1873), and further elaborated in the twentieth century (e.g., Kober 1921; Jeffreys 1924; Stille 1924; Wilson 1954), may be of help here. This hypothesis was proposed as an explanation of mountain building processes on Earth long before the acceptance of plate tectonics and remains peculiarly appropriate to explain the tectonic evolution of Mercury, which likely has been a one-plate planet since the formation of its earliest crust. Those early ideas and concepts used on Earth before plate tectonics may thus hold clues to the early phase of global contraction and how it is expressed in the preserved geology of Mercury (and, indeed, other one-plate planets).

The contracting Earth hypothesis served to explain and tie together many observations of thrust faulting, folding, and mountain building, as well as magmatism and volcanism. In its simplest form, contraction of the planetary interior was proposed to lead to a "crumpling" of the outer shell of Earth (Fig. 13A), akin mechanically (if not thermally) to the shriveled skin of an old apple. If, however, the main contraction occurred in the outer shell without much contribution from contraction of the interior, Otto Ampferer (Ampferer 1928) suggested that extension would be triggered, in turn facilitating subsequent voluminous volcanism (Fig. 13B), an idea originally proposed by Jean-Claude Delamétherie. Delamétherie (1795, pp. 164-177) seems to have been the first in the eighteenth century to discuss this topic in detail and drew from that discussion several geometric and kinematic consequences. Following the footsteps of Georges-Louis Leclerc, Comte de Buffon, he wrote: "The surface of Earth cools more than its interior and the contraction must generate cracks and form cliffs and escarpments" (Delamétherie 1795, p. 367). Delamétherie's conclusion was eminently sensible, and we encounter the same deduction three decades later in the writings of his compatriot Pierre Louis Antoine Cordier (1777-1861) (Cordier 1827) and about a century and a half later in the writings of Otto Ampferer (1875-1947). Ampferer (1928) invoked a hybrid scenario to explain shortening and magmatism and volcanism without the need for a 
Fig. 13. Possible end-member scenarios of planetary contraction (after Ampferer, 1928). (A) Contraction of the planetary interior with a rigid outer shell. The contraction leads to a crumpling of the outer shell. (B) A hot planetary interior with rapidly contracting outer shell produces extension at the surface. The extension triggers magmatism and volcanism. (C) Progression of contraction from the surface toward the interior leads to shortening in the outer shell. This figure is in the public domain.
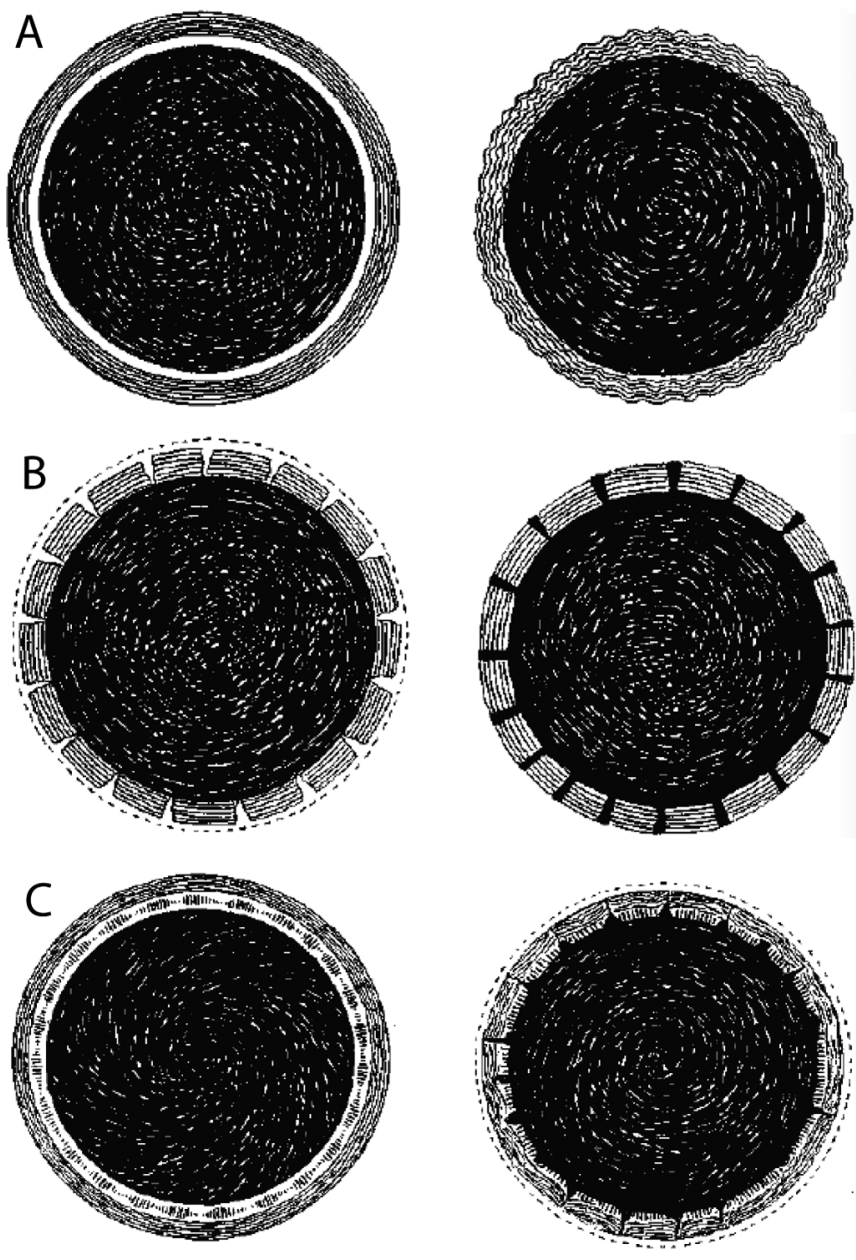

pervasive crumpling of the outer shell, whereby conditions change as the contraction progresses from surface to depth (Fig. 13C). These end-member cases highlight how shortening and magmatism and volcanism may have taken place on a contracting planet. But as the diversity of deformation observed on Earth was not compatible with either of these two scenarios of contraction (Figs. 13A, 13B), the contraction hypothesis was criticized long before the advent of the concept of plate tectonics (Dutton 1874; Ampferer 1928).

Hypothetical early and advanced stages of Mercury's tectonic evolution after the onset of global contraction are depicted in Fig. 14 in two schematic cross sections. In the early stage (Fig. 14A), it is assumed that the main thermally induced contraction occurred within the early lithosphere, analogous to the scenario of the hot interior of Earth with a rapidly contracting outer shell in Fig. 13B. Such contraction thus could have triggered widespread extension, which led to normal faulting, rifting, and associated lithospheric thinning, which in turn could trigger magmatism and major volcanism through pressure-release melting or by offering readily accessible conduits through which existing magma could ascend. This phase, which we name the "Delamétherian phase" in Mercury's evolution, could have temporally overlapped with other major processes at that time, such as a heavy meteoroid bombardment and perhaps even planetary despinning. Much of the crust may have been emplaced during this stage by a series of effusive volcanic eruptions and a succession of plains deposits (Denevi et al. 2009). Plains volcanism on Mercury ceased near the time when global-contraction-induced thrust faulting was initiated (Byrne et al. 2016a), i.e., during what we call the "Beaumontian phase", after Léonce Élie de Beaumont, who first recognized in 1829 (Élie de Beaumont 1829-1830) the importance of global contraction for the origin of structures of shortening.

The stage of advanced cooling and contraction involves the onset of crustal shortening dominated by the overthrusting of low-lying areas (first described as "Überschiebung der Tiefen", by Suess 1909; Şengör et al. 1993). Deformation in this stage could include major, deep-seated thrust faults, some of which demarcate the transition from high-standing to low-lying terrains, longwavelength thrust-fault-related basement folds, and thin-skinned folding and thrusting in low-lying volcanic plains (Fig. 14B). Many high-terrain-bounding thrust faults and smooth plains structures occur in spatial association with one another, and they frequently share the same structural trends (Byrne et al. 2014). Those examples may be structural systems where the smaller, smooth-plains structures root into the larger high-terrain-bounding thrust faults (Byrne et al. 2014, 2018; Fig. 14B), a common structural arrangement in terrestrial orogenic settings (see references given by Byrne et al. 2018).

In such tectonic settings, the deeply rooted thrust faults correspond to what Stille (1920) called germanotype structures, which typically consist of a single major fault accommodating strain by block faulting, where the majority of deformation is localized in a narrow zone along the major fault. In contrast, the smooth plains structures are, per Stille (1920), alpinotype faults that involve detachment folding, with the height of accumulated topography indicating the depth of the detachment horizon. The distinction between structures made with Stille's terminology, as opposed to the terms "lobate scarp" and "wrinkle ridge", specifically introduces a structural meaning and a testable interpretation for these structures.

\section{Applications to Venus}

With respect to planetary size, interior constitution, and overall composition, Venus is the most similar to Earth among the inner planets. The distribution of impact craters on Venus, which is indistinguishable from a random distribution (Schaber et al. 1992), makes terrestrial-style plate tectonics unlikely to have occurred after crater emplacement, but the low spatial density of craters indicates that the planet has likely been geologically active in the recent past. Indeed, Venus is a heavily deformed world, arguably to a greater extent than any other inner solar system body aside from Earth. Early radar observations of the second planet revealed an abundance of landforms interpreted to be normal faults and thrust-fault-related folds (e.g., Masursky et al. 1980; Campbell et al. 1983, 1984). Although there is no evidence of terrestrial-style plate tectonics (i.e., with spreading and subduction of oceanic-like plates) on Venus (e.g., Solomon et al. 1991), it is clear that considerable lithospheric extension and shortening has occurred. In places, tectonic deformation has been broadly distributed spatially; in other areas, strain has been concentrated into narrow curvilinear zones (Solomon et al. 1991).

As for Mercury, however, the terminology used for Venus tectonics frequently differs from that applied to terrestrial structures, limiting the accessibility of findings for Venus for those who study other worlds. For example, portions of the Venus surface that show the greatest amount of tectonic deformation are termed "tesserae" (e.g., Bindschadler and Head 1988), having formerly been called "parquet terrain" (Barsukov et al. 1986). These names arose because of the profound structural complexity of 
Fig. 14. Stages of the tectonic evolution of Mercury shown as schematic cross sections. (A) A hypothetical early stage in planetary history, where effusive volcanic plains form under contraction-related extension, planetary despinning, and meteoroid bombardment. (B) Stage of advanced cooling and contraction: onset of crustal shortening dominated by overthrusting of low-lying areas. Solid white lines represent active faults; dashed white lines denote inactive faults. [Color online.]
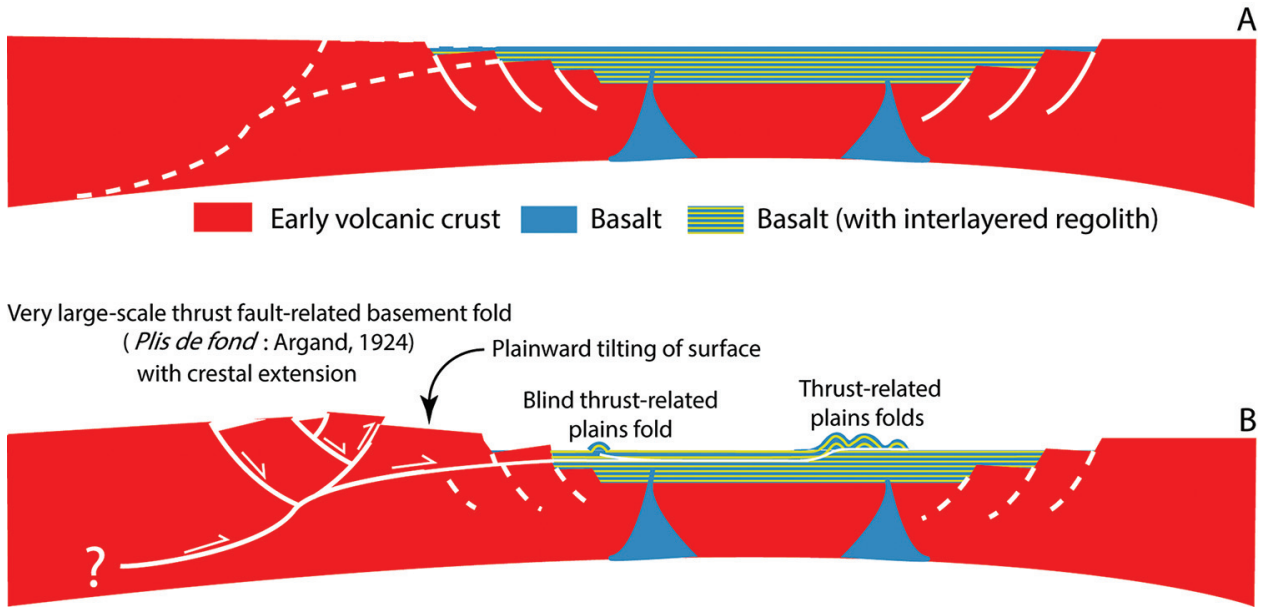

Fig. 15. Magellan synthetic aperture radar images of shortening and extensional deformation on Venus. (A) Vaidilute Rupes is a broad, linear rise, tens of kilometres in width and many hundreds of kilometres long, that is typically described as a ridge belt, representing an example of shortening deformation. (B) Long systems of structures hosting landforms indicative of normal faults forming grabens and half grabens typically labeled fracture belts or groove belts.

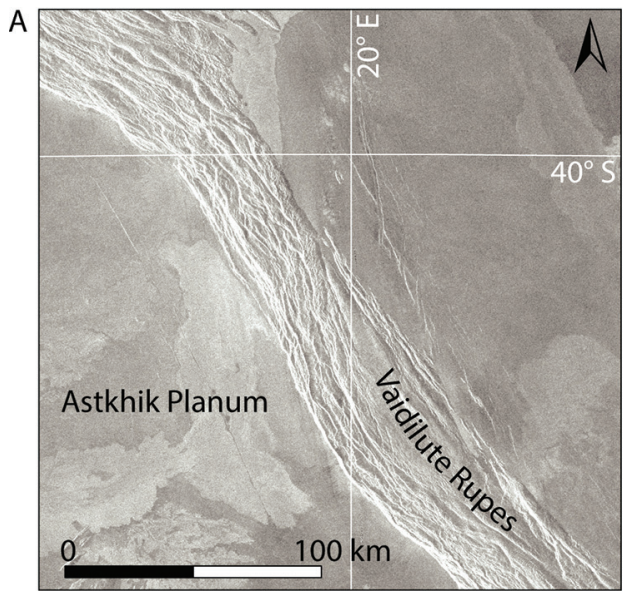

these regions, even though they contain features commonly recognized on Earth (such as faults of various types, including grabens, as well as antiforms, synforms, and even shear zones with pronounced foliations) (Hansen and Willis 1996; Kumar 2005). But terms have been applied to some of the structures within tessera units on Venus, such as "ribbon terrain" (e.g., Hansen and Willis 1998), which do not have an obvious counterpart in the Earthbased structural geological nomenclature. Although such terms arose, at least in part, because available data were not sufficient to resolve unambiguously the nature (e.g., "ribbon") or origin (e.g., "tessera") of these structures and units, the adoption of terms not otherwise utilized for other planets, including Earth, once again potentially limits the ease with which these terms can be understood by those for whom Venus is not a familiar world.

Similarly, narrow, curvilinear bands of features interpreted as shortening structures that have accommodated crustal thickening have been termed "ridge belts" (e.g., Barsukov et al. 1986; Squyres et al. 1992) but are, by this interpretation, orogenic belts (Fig. 15A). These belts are typically manifest as broad, linear rises a few hundred metres in relief, tens of kilometres in width, and many hundreds of kilometres long (Squyres et al. 1992); there are often multiple anastomosing secondary arches and ridges super-

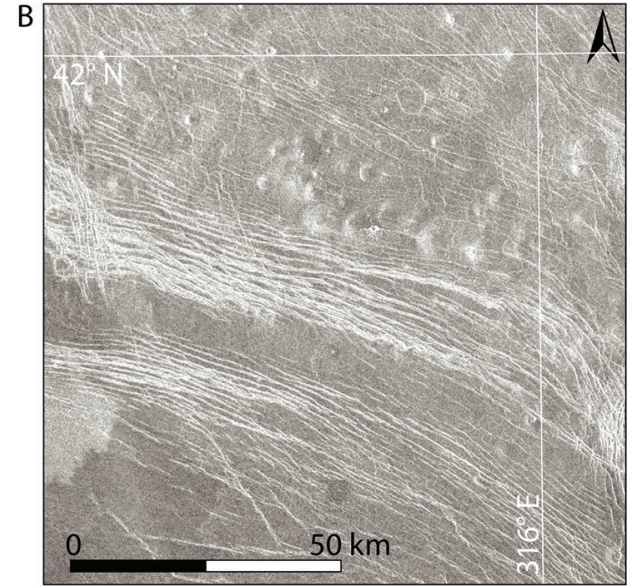

posed on the larger rise. Although they lack the dimensions of major orogenic belts on Earth, these systems of structures almost certainly correspond to shortening strains and thus are orogenic belts of smaller dimensions, such as those on Spitzbergen, the Transverse Ranges in California, or the Nan Shan in northeastern Tibet (Şengör 1990b). Larger mountain ranges have long been recognized on Venus, and given their sizes are generally referred to as such (e.g., Barsukov et al. 1986; Solomon et al. 1991). Notably, Venus also possesses smaller shortening structures that correspond to the classic wrinkle ridge morphology documented on the Moon, Mars, and Mercury, and which, unlike the larger ridge belts, do not denote much shortening strain. By analogy with these other rocky worlds, these smaller shortening structures on Venus may primarily reflect subsidence of the volcanic plains in which they are widely found.

The extensional counterparts to the orogenic belts are long systems of structures that have variously been labeled "fracture belts" or "groove belts" (e.g., Squyres et al. 1992; Ivanov and Head 2011) (Fig. 15B). These systems host normal faults that form grabens and half grabens, which show subparallel and anastomosing surface ruptures as well as evidence for fault linkage. Although most examples have dimensions comparable with the orogenic 
belts, some of these extensional systems combine to form arrays thousands of kilometres long that may be underlain by dike swarms (e.g., Ivanov and Head 2013). In any case, the structures that make up the extensional belts indicate stretching of the crust and so, by any measure related to Earth, comprise rift zones. Of note, much larger regions characterized by major extensional strains, vast volumes of proximal volcanic deposits, and strong gravity and geoid anomalies that suggest deep-seated compensation consistent with mantle upwelling (e.g., Solomon et al. 1991; James et al. 2013) are also referred to as "rifts" and "rift zones" (e.g., Ivanov and Head 2011), and may be loosely analogous to mid-ocean ridges on Earth, albeit not within a coupled spreadingsubduction system (Ghail 2015). The term "rift zone" therefore is, at least conventionally, applied only to extensional systems above some (nonspecific) spatial scale for Venus.

\section{Applications to Mars}

Mars is a geologically diverse planet, displaying many large- and small-scale physiographic features that have been shaped by volcanic, glacial, fluvial, eolian, and tectonic processes. With the insight that plate tectonics has long operated on Earth, many researchers hypothesized and tested whether similar tectonics also operate or operated on other rocky bodies (e.g., Anderson 1981; Sleep 1994; Yin 2012). Processes with phenomena similar to those accompanying plate tectonics on Earth have also been invoked to explain many peculiar large-scale physiographic Martian features, such as the dichotomy boundary separating the comparatively lightly cratered northern lowlands from the heavily cratered and thus older southern highlands, the Tharsis large igneous province with its many volcanic shields, or Valles Marineris as the largest canyon system known in our solar system. For example, Şengör and Jones (1975) suggested a plate tectonics model to account for a structural interpretation of images returned by Mariner 9. In that model, an elongated depression in the Phoenicis Lacus area was interpreted as a trench into which a postulated Tharsis plate was obliquely subducted. Although the model accounted for the dichotomy between the smooth lowland plains in the north and cratered highlands in the south, as well as the structural and volcanic lineations in the region, higherresolution data acquired later did not support this interpretation. To date, no plate tectonic model for Mars has been widely accepted, and the majority of landforms can be explained by processes not requiring multiple tectonic plates with substantial horizontal mobility.

Mars had, and likely still has, a hydrologic cycle, and thus the provenance and the effects of water must be considered in the tectonic assessment of the Red Planet. The presence of liquid water plays an important role in the rheology of rock participating in tectonic processes, for the strength of faults, for the formation of a wide variety of minerals that may participate in deformation processes, and for the dissolution of minerals that gives rise to karst features. The last of these processes, in particular, is of interest because the substantial volumes of frozen water stored in the Martian subsurface may allow for the development of thermokarst if sudden melting occurs from an impact or magmatic event.

Recent thermokarst on Earth can be triggered by the rapid melting of permafrost in response to global atmospheric warming. The sudden release of methane to the atmosphere produces thermokarstic landforms that are not unlike those of a typical karst landscape and include obruks (karst pits), dolinas, and even uvalas. Prominent examples include the large Batagaika crater in Siberia, or the many smaller round craters that pockmark the Siberian permafrost landscape. On Mars, patterned ground and pingos (Carr and Schaber 1977; Burr et al. 2009) indicate that permafrost is widespread, and indeed large quantities of frozen water are inferred to be present in the subsurface (Clifford et al. 2010; Stuurman et al. 2016; Weiss and Head 2017). Any heat source pres-
Fig. 16. Simulated westward view of Valles Marineris from space constructed with Mars Orbiter Laser Altimeter (MOLA) topography and High Resolution Stereo Camera (HRSC) images. The portion of Valles Marineris shown here is over $2000 \mathrm{~km}$ long. [Color online.]

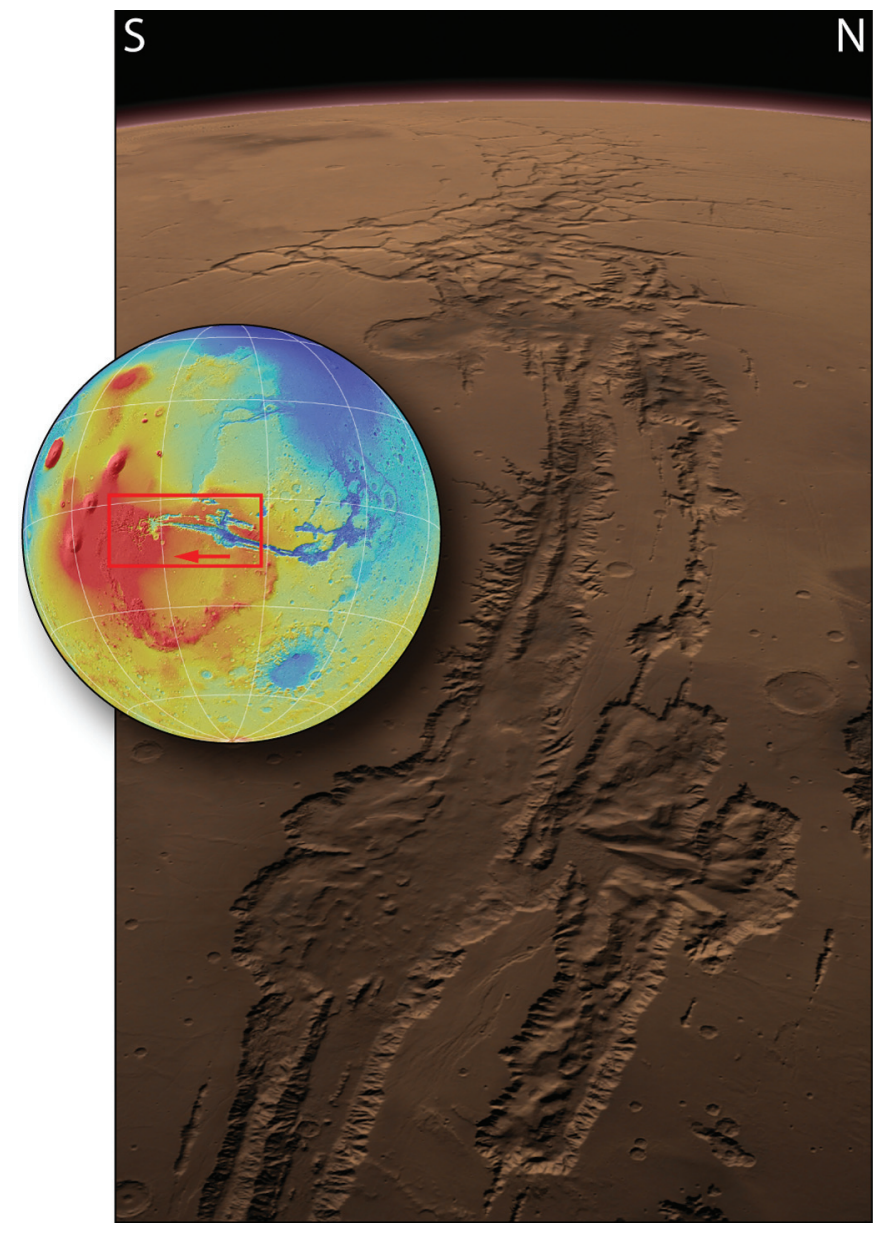

ent on Mars would therefore have the potential to trigger melting of subsurface ices, also giving rise to thermokarst. Of note, scenarios of dikes intruding into ice-rich rock units have been invoked to explain many of the large-scale outflow channels, chaos terrain, and flood deposits (McKenzie and Nimmo 1999) across the planet. Valles Marineris (Fig. 16), where dikes have been detected (Flahaut et al. 2011; Brustel et al. 2017), is a candidate site where dikeinduced melting could have produced not only large amounts of water to form outflow channels, but also the large canyon system of Valles Marineris itself.

By this hypothesis, the melting of ice, the associated collapse of rock volume that hosted the ice, and the discharge of water together served to produce Valles Marineris (Şengör et al. 2016). If so, Valles Marineris would be the largest polje (Şengör et al. 2016) known in our solar system. This view is supported by the karstic geomorphology of the canyon walls that resemble typical collapse and mass-wasting scarps (Şengör et al. 2016) that are unlike those associated with typical rift structures, the prevailing explanation for the feature's origin (Şengör and Jones 1975; Masson 1977; Frey 1979; Mège and Masson 1996; Mège et al. 2003). In addition, numerical (McKenzie and Nimmo 1999) and analogue (Jackson et al. 2011; Şengör et al. 2016) modeling reveals that the transfer of magmatic heat to permafrost, as well as subsequent collapse caused by melting and discharge of subsurface ice, can reproduce all landforms present in Valles Marineris without the need to invoke a sequence of unrelated processes. 
After Mercury, Mars is the second smallest planet in our solar system and presumably has a thick present lithosphere, similar to that of Mercury (Fig. 2). This similarity implies that both of these bodies have experienced substantial cooling and thus must have contracted. Mercury shows ample evidence (in the form of its fault-related folds) for having undergone a decrease in radius of up to 7-9 km (Byrne et al. 2014; Klimczak 2015). In contrast, the surface geological record of Mars, although also demonstrating ample evidence for shortening, also boasts evidence of structures that are not compatible with a sustained period of interior cooling and global contraction. Among those features are long-lived volcanoes and their corresponding lava flows (e.g., Greeley and Spudis 1981), grabens (Fig. 5A), and opening-mode fractures, such as extensional b or a-c joints (Okubo 2010) or dikes (Schultz et al. 2004). Additionally, many lava flows and grabens are morphologically fresh, whereas shortening structures that could have been formed by contraction are superposed by heavily degraded craters and thus are more ancient. This pattern shows that extension persisted well into more recent geologic times. Nahm and Schultz (2011) calculated that extensional strain accommodated by grabens is likely larger than the strain contributed by a radius decrease.

These seemingly conflicting observations raise the question as to whether Mars experienced a period of global contraction. If so, why did the contraction stop and allow for the widespread effusive volcanism and tectonic extension? And if not, why does Mars show many large, globally distributed thrust-fault-related landforms (Klimczak et al. 2018)? Such landforms show striking similarities in size and morphology to structures attributed to global contraction on Mercury, with both deeply rooted (germanotype) and shallow (alpinotype) structures and their assemblages present. Adaptation and application of the Holmesian method of drawing profiles across shortening landforms (Fig. 8) to structures on Mars (e.g., Mueller et al. 2014; Klimczak et al. 2018) has revealed gradual changes in fault-related fold geometry across each of the analyzed structures, indicating that these thrust systems are large, deeply rooted structures analogous to basement uplifts of the Laramide orogeny in the western United States (e.g., Matthews 1978; Erslev 1986; Stone 1993) or the Late Cretaceous, intraplate, thrust-related basement uplifts and inversion tectonics of central Europe (the so-called "Saxonische Schollentektonik" or Saxonian block tectonics) (e.g., Ziegler et al. 1995; Kley 2013). Individual mountain ranges that may structurally compare well with the deeply rooted structures on Mars thus include the Elk Mountains, Colorado, where Holmes (1876) first systematically studied variations of deformation along landform, the Wind River Range in central Wyoming, as previously suggested by Mueller et al. (2014), or nearby mountain ranges such as the Beartooth or Bighorn Mountains, the East Kaibab Monocline (Byrne et al. 2016b), or the Harz Mountains in Germany (Klimczak et al. 2018).

\section{Concluding remarks}

Earth is commonly regarded as special among the planetary bodies in our solar system, as it is the only planet known to possess plate tectonics. With the recognition of a lack of Earth-style plate tectonics on the other rocky planets, many planetary scientists invented new terms to describe, categorize, and analyze surface structures. But structural and tectonic phenomena resulting from shortening and stretching of the rocky rinds of Mercury, Venus, and Mars are not substantially different from those observed and described on Earth, as all of these bodies are rocky planets possessing lithospheres that share many geophysical and geochemical characteristics. We have shown here that numerous phenomena observed on the rocky planets have previously been described on Earth and that some historic hypotheses, later proven not to be valid on Earth, seem applicable to the study of tectonics on the other rocky planets. Even if these hypotheses turn out not to have global applicability, the interpretations of individual structures seem robust and, as happened on Earth, they could be easily placed within the framework of newer hypotheses. But it is critical that the experience acquired on Earth through geomorphology and structural geology be given first consideration in the interpretation of features on our neighboring rocky planets and moons. Therefore, we propose a few recommendations for future analysis of planetary tectonics:

(1) Take advantage of what has been learned about structures on Earth. Among all the planetary bodies, Earth has been investigated the longest and in the greatest detail. Thus, there are many well-studied analogue sites, many hypotheses that have been published, and many historic concepts pre-dating plate tectonics that although no longer valid for Earth may be still be of value for the study of planets without plate tectonics. The idea of the theory of the contracting Earth, for instance, provides a global-scale example of an historic concept that finds applicability on Mercury and even on Mars and the Moon, and structures in intraplate tectonic settings may serve as analogue field sites for the characterization and understanding of landforms on these bodies.

(2) Adopt genetic naming of tectonic landforms, as is done for terrestrial structures. Of course, as for terrestrial structures, such genetic naming and the accompanying interpretation for the origin of the structure follows only after careful description and consideration of all possible observations. Such an approach is currently not widely followed in planetary mapping, but the naming of planetary landforms on the basis of genetic instead of purely empirical, generic descriptions would allow us to draw analogies between structures on Earth and those on other rocky worlds much more readily, and would more effectively bring together scientists studying Earth and the other planets. A given genetic interpretation may be wrong, to some degree or even in its entirety, but progress in science is made by falsifying hypotheses. Hypotheses are like flashlights; they illuminate the places to which we direct them, but they do not tell us what they illuminate. It is our job to figure out what we are looking at. But with no light, we cannot see!

All geological maps are interpretations, and no mapmaker should be afraid of interpreting tectonic landforms. Such interpretations can be tested, and if disproved then re-interpreted with a modified or new hypothesis. Of course, genetic naming of landforms is not relevant only for rocky worlds but should be extended to all planetary bodies with solid surfaces, including icy moons, dwarf planets, and even asteroids. An example mentioned above is the group of shortening landforms on planetary surfaces and their common binning into the generic categories of wrinkle ridges, high-relief ridges, and lobate scarps, when all three such landform types occur in the same tectonic settings, transition into one another, and can show ambiguous criteria that fit multiple or even none of the categories. In contrast, naming thrust faults or thrust-fault-related landforms for what they are, especially when tied to a specific tectonic setting, allows geologists studying Earth to draw a mental picture of such landforms and the general subsurface geometry of their structures.

(3) Map to test hypotheses and adopt the standard symbolism for faults and folds. Producing a structural map without testable hypotheses is not useful for the characterization of the tectonics of the mapped area. Of course, a structural map is a scientific interpretation that comes with the many challenges of such interpretation, including disagreement about the interpretation among mappers or the tendency to search for information in a way that confirms a mapmaker's preexisting hypotheses (i.e., confirmation bias) during mapping. Therefore, it is preferable to define mapping criteria clearly before carrying out mapping and then to apply the criteria consistently using the standard symbols for structures as they have been used in mapping Earth. 


\section{Acknowledgements}

We thank Editor-in-Chief Ali Polat and Guest Editor John Dewey for handling our manuscript. We also thank Richard Ghail and an anonymous reviewer for constructive reviews, which helped to improve the content and clarity of the paper.

\section{References}

Ampferer, O. 1928. Beiträge zur Auflösung der Mechanik der Alpen, 3. Fortsetzung. Jahrbuch der Geologischen Bundesanstalt, Wien, 78: 327-355.

Anderson, D.L. 1981. Plate tectonics on Venus. Geophysical Research Letters, 8: 309-311. doi:10.1029/GL008i004p00309.

Angelier, J. 1994. Fault slip analysis and palaeostress reconstruction. In Continental Deformation. Edited by P.L. Hancock. Pergamon Press, Oxford, UK, pp. 53-100.

Argand, É. 1911. Les nappes de recouvrement des Alpes Pennines et leurs prolongements structuraux. Matériaux pour la Carte Géologique de la Suisse, nouvelle série, 31e livraison, 26 pp.

Argand, É. 1912. Coupes géologiques dans les Alpes Occidentales interprétée par Émile Argand, 1902-1911. Pl 1: Les nappes de recouvrement dans les Alps occidentales et les territoires environnents. Essai de carte structurale, 1:500,000; Pl. II: Neuf coupes à travers les Alpes occidentales, 1:400,000; P1. III the same; Pl. IV Les grands plis couchés dans les Alpes Pennines, 1:500,000: Matériaux pour la Carte Géologique de la Suisse, nouvelle série, 27e livraison.

Argand, É. 1924. La tectonique de l'Asie. In International Geological Congress, $13^{\text {th }}$ Session, Liège, Vaillant-Carmanne, 1: 171-372.

Argand, É. 1926. Sur l'arc des alpes occidentales. Eclogae Geologicae Helvetiae, 14: 145-191.

Argand, É. 1934. La zone pennique. In Guide Géologique de la Suisse, fascicule III Introductions générales. Wepf \& Cie, Basel, pp. 149-189.

Baioni, D., Zupan Hajna, N., and Wezel, F.C. 2009. Karst landforms in a Martian evaporitic dome. Acta Carsologica, 38: 9-18.

Baioni, D., Tramontana, M., and Zupan Hajna, N. 2017. Karst landforms within Noctis Labyrinthus, Mars. Acta Carsologica, 46: 73-82.

Banks, M.E., Xiao, Z., Watters, T.R., Strom, R.G., Braden, S.E., Chapman, C.R., et al. 2015. Duration of activity on lobate scarp thrust faults on Mercury. Journal of Geophysical Research: Planets, 120: 1751-1762. doi:10.1002/(ISSN) 2169-9100.

Barsukov, V.L., Basilevsky, A.T., Burba, G.A., Bobinna, N.N., Kryuchkov, V.P., Kuzmin, R.O., et al. 1986. The geology and geomorphology of the Venus surface as revealed by the radar images obtained by Veneras 15 and 16 . Journal of Geophysical Research, 91: D378-D398.

Bilotti, F., and Suppe, J. 1999. The global distribution of wrinkle ridges on Venus. Icarus, 139: 137-157. doi:10.1006/icar.1999.6092.

Bindschadler, D.L., and Head, J.W. 1988. Models for the origin of tessera terrain on Venus. Lunar and Planetary Science, 19: 78-79.

Blair, D.M., Freed, A.M., Byrne, P.K., Klimczak, C., Prockter, L.M., Ernst, C.M., et al. 2013. The origin of graben and ridges in Rachmaninoff, Raditladi, and Mozart basins, Mercury. Journal of Geophysical Research: Planets, 118: 47-58. doi:10.1029/2012JE004198.

Brace, W.F., and Kohlstedt, D.L. 1980. Limits on lithospheric stress imposed by laboratory experiments. Journal of Geophysical Research, 85: 6248-6252. doi:10.1029/JB085iB11p06248.

Brustel, C., Flahaut, J., Hauber, E., Fueten, F., Quantin, C., Stesky, R., and Davies, G.R. 2017. Valles Marineris tectonic and volcanic history inferred from dikes in eastern Coprates Chasma. Journal of Geophysical Research: Planets, 122: 1353-1371. doi:10.1002/2016JE005231.

Bryan, W.B. 1973. Wrinkle-ridges as deformed surface crust on ponded mare lava. In Proceedings of the Fourth Lunar Science Conference, pp. 93-106.

Bucher, W.H. 1933. The Deformation of the Earth's Crust. Princeton University Press, Princeton, N.J.

Buck, R. 1988. Flexural rotation of normal faults. Tectonics, 7: 959-973. doi:10. 1029/TC007i005p00959.

Burr, D.M., Tanaka, K.L., and Yoshikawa, K. 2009. Pingos on Earth and Mars. Planetary and Space Science, 57: 541-555. doi:10.1016/j.pss.2008.11.003.

Byerlee, J. 1978. Friction of rocks. Pure and Applied Geophysics, 116: 615-626. doi:10.1007/BF00876528.

Byrne, P.K., Klimczak, C., Şengör, A.M.C, Solomon, S.C., Watters, T.R., and Hauck, S.A., II. 2014. Mercury's global contraction much greater than earlier estimates. Nature Geoscience, 7: 301-307. doi:10.1038/ngeo2097.

Byrne, P.K., Klimczak, C., McGovern, P.J., Mazarico, E., James, P.B., Neumann, G.A., et al. 2015. Deep-seated thrust faults bound the Mare Crisium lunar mascon. Earth and Planetary Science Letters, 427: 183-190. doi:10.1016/j.eps1.2015.06. 022 .

Byrne, P.K., Ostrach, L.R., Fassett, C.I., Chapman, C.R., Denevi, B.W., Evans, A.J., et al. 2016a. Widespread effusive volcanism on Mercury likely ended by about 3.5 Ga. Geophysical Research Letters, 43: 7408-7416. doi:10.1002/2016GL069412.

Byrne, P.K., Klimczak, C., and LaFond, J.K. 2016b. The East Kaibab monocline: A Terran lobate scarp? Lunar and Planetary Science, 47: Abstract 1022.

Byrne, P.K., Klimczak, C., and Şengör, A.M.C. 2018. The tectonic character of Mercury. In Mercury - The View after MESSENGER. Edited by S.C. Solomon,
L.R. Nittler, and B.J. Anderson. Cambridge University Press, Cambridge, UK, pp. 249-286.

Campbell, D.B., Head, J.W., Harmon, J.K., and Hine, A.A. 1983. Venus: Identification of banded terrain in the mountains of Ishtar Terra. Science, 221: 644647. doi:10.1126/science.221.4611.644.

Campbell, D.B., Head, J.W., Harmon, J.K., and Hine, A.A. 1984. Venus: Volcanism and rift formation in Beta Regio. Science, 226: 167-170. doi:10.1126/science. 226.4671.167.

Carr, M.H., and Schaber, G.G. 1977. Martian permafrost features. Journal of Geophysical Research, 82: 4039-4054. doi:10.1029/JS082i028p04039.

Chapman, D.S. 1986. Thermal gradients in the continental crust. In The Nature of the Lower Continental Crust. Edited by J.B. Dawson, D.A. Carswell, J. Hall, and K.H. Wedepohl. The Geological Society Special Publications, 24: 63-70.

Clifford, S.M., Lasue, J., Heggy, E., Boisson, J., McGovern, P., and Max, M.D. 2010. Depth of the Martian cryosphere: Revised estimates and implications for the existence and detection of subpermafrost groundwater. Journal of Geophysical Research, 115: E07001. doi:10.1029/2009JE003462.

Cloos, H. 1936. Einfuhrung in die Geologie - Ein Lehrbuch der Inneren Dynamik. Gebrüder Borntraeger, Berlin, Germany. www.borntraeger-cramer.de.

Cordier, P.L.A. 1827. Essai sur la température de l'intérieur de la terre. Mémoires de l'Academie des Sciences pour l'année 1827, 7: 473-556.

Cowie, P.A., Scholz, C.H., Roberts, G.P., Faure, Walker, J.P., and Steer, P. 2013. Viscous roots of active seismogenic faults revealed by geologic slip rate variations. Nature Geoscience, 6: 1036-1040. doi:10.1038/ngeo1991.

Crane, K.T., and Klimczak, C. 2017. Timing and rate of global contraction on Mercury. Geophysical Research Letters, 44: 3082-3089. doi:10.1002/ 2017 GL072711.

Crane, K.T., and Klimczak, C. 2019. Tectonic patterns of shortening landforms in Mercury's northern smooth plains. Icarus, 317: 66-80. doi:10.1016/j.icarus. 2018.05.034.

Cvijić, J. 1893. Das Karstphänomen — Versuch einer Morphologischen Monographie. Geographische Abhandlungen, 5: 217-329.

Cvijić, J. 1900. Morphologische und Glaciale Studien aus Bosnien der Hercegovina and Montenegro. I. Theil: Das Hochgebirge und die Cañonthäler. Abhandlungen der K. K. Geographischen Gesellschaft in Wien, 2: 3-93 (+9 plates).

Cvijić, J. 1901. Morphologische und Glaciale Studien aus Bosnien der Hercegovina and Montenegro. II. Theil: Die Karstpoljen. Abhandlungen der K. K. Geographischen Gesellschaft in Wien, 3: 5-85.

Cvijić, J. 1960. La Géographie des Terrains Calcaires. Académie des Sciences et des Arts, Monographies, Vol. 341. Classe des Sciences Mathématiques et Naturelles, 26: 212

Czudek, T., and Demek, J. 1970. Thermokarst in Siberia and its influence on the development of lowland relief. Quaternary Research, 1: 103-120. doi:10.1016/ 0033-5894(70)90013-X.

Dana, J.D. 1873. On some results of the Earth's contraction from cooling, including a discussion of the origin of mountains and the nature of the Earth's interior. American Journal of Science, 5: 423-443. doi:10.2475/ajs.s3-5.30.423.

Delamétherie, J.-C. 1795. Théorie de la Terre. Maradan libraire, Paris.

Denevi, B.W., Robinson, M.S., Solomon, S.C., Murchie, S.L., Blewett, D.T., Domingue, D.L., et al. 2009. The evolution of Mercury's crust: A global perspective from MESSENGER. Science, 324: 613-618. PMID:19407196.

Dutton, C.E. 1874. A criticism of the contractional hypothesis. American Journal of Science, 8: 113-123. doi:10.2475/ajs.s3-8.44.113.

Dzurisin, D. 1978. The tectonic and volcanic history of Mercury as inferred from studies of scarps, ridges, troughs, and other lineaments. Journal of Geophysical Research, 83: 4883-4906. doi:10.1029/JB083iB10p04883.

Élie de Beaumont, L. 1829. Faits pour Servir a l'Histoire des Montagnes de l'Oisans. Mémoires de la Société d'Histoire Naturelle de Paris, pp. 1-32.

Élie de Beaumont, L. 1829-1830. Recherches sur quelques-unes des Révolutions de la surface du globe, présentant différens exemples de coïncidence entre le redressement des couches de certains systèmes de montagnes, et les changemens soudains qui ont produit les lignes de demarcation demarcation qu'on observe entre certains étages consécutifs des terrains de sédiment. Annales des Sciences Naturelles, 18: 284-417; 19: 177-240.

Élie de Beaumont, L. 1852. Notice sur les Systèmes de Montagnes, tome III: P. Bertrand, Paris, pp. 1069-1543.

Erslev, E. 1986. Basement balancing of Rocky-Mountain foreland uplifts. Geology, 14: 259-262. doi:10.1130/0091-7613(1986)14<259:BBORMF>2.0.CO;2.

Flahaut, J., Mustard, J.F., Quantin, C., Clenet, H., Allemand, P., and Thomas, P. 2011. Dikes of distinct composition intruded into Noachian-aged crust exposed in the walls of Valles Marineris. Geophysical Research Letters, 38: L15202. doi:10.1029/2011GL048109.

Ford, D., and Williams, P. 2007. Karst Hydrogeology and Geomorphology. Wiley, Hoboken, N. J.

Freed, A.M., Blair, D.M., Watters, T.R., Klimczak, C., Byrne, P.K., Solomon, S.C., et al. 2012. On the origin of graben and ridges within and near volcanically buried craters and basins in Mercury's northern plains. Journal of Geophysical Research, 117: E00L06. doi:10.1029/2012JE004119.

Frey, H. 1979. Martian canyons and African rifts: Structural comparisons and implications. Icarus, 37: 142-155. doi:10.1016/0019-1035(79)90122-2.

Ghail, R. 2015. Rheological and petrological implications for a stagnant lid regime on Venus. Planetary and Space Science, 113-114: 2-9. doi:10.1016/j.pss. 2015.02.005. 
Golombek, M.P., Plescia, J.B., and Franklin, B.J. 1991. Faulting and folding in the formation of planetary wrinkle ridges. Proceedings of Lunar and Planetary Science, 21: 679-693.

Golombek, M.P., Anderson, F.S., and Zuber, M.T. 2001. Martian wrinkle ridge topography: Evidence for subsurface faults from MOLA. Journal of Geophysical Research, 106: 23811-23821. doi:10.1029/2000JE001308.

Greeley, R., and Spudis, P.D. 1981. Volcanism on Mars. Reviews of Geophysics, 19: 13-41. doi:10.1029/RG019i001p00013.

Grott, M., and Breuer, D. 2008. The evolution of the Martian elastic lithosphere and implications for crustal and mantle rheology. Icarus, 193: 503-515. doi: 10.1016/j.icarus.2007.08.015.

Handin, J. 1969. On the Coulomb-Mohr failure criterion. Journal of Geophysical Research, 74: 5343-5348. doi:10.1029/JB074i022p05343.

Hansen, V.L., and Willis, J.A. 1996. Structural analysis of a sampling of tesserae: Implications for Venus geodynamics. Icarus, 123: 296-312. doi:10.1006/icar. 1996.0159 .

Hansen, V.L., and Willis, J.J. 1998. Ribbon terrain formation, southwestern Fortuna Tessera, Venus: Implications for lithosphere evolution. Icarus, 132: 321343. doi:10.1006/icar.1998.5897.

Holmes, W.H. 1876. Report on the geology of the northwestern portion of the Elk Range. U.S. Geological and Geographical Survey of the Territories, $8^{\text {th }}$ Annual Report, pp. 59-71.

Huntington, K.W., and Klepeis, K.A. 2018. Challenges and opportunities for research in tectonics: Understanding deformation and the processes that link Earth systems, from geologic time to human time. A community vision document submitted to the U.S. National Science Foundation. Available from http://hdl.handle.net/1773/40754.

Ivanov, M.A., and Head, J.W. 2011. Global geological map of Venus. Planetary and Space Science, 59: 1559-1600. doi:10.1016/j.pss.2011.07.008.

Ivanov, M.A., and Head, J.W. 2013. The history of volcanism on Venus. Planetary and Space Science, 84: 66-92. doi:10.1016/j.pss.2013.04.018.

Jackson, M.P.A., Adams, J.B., Dooley, T.P., Gillespie, A.R., and Montgomery, D.R. 2011. Modeling the collapse of Hebes Chasma, Valles Marineris, Mars. Geological Society of America Bulletin, 123: 1596-1627. doi:10.1130/B30307.1.

Jaeger, J.C., Cook, N.G., and Zimmerman, R.W. 2007. Fundamentals of Rock Mechanics (4th edition). Blackwell Publishing, Malden, Massachusetts.

James, P.B., Zuber, M.T., and Phillips, R.J. 2013. Crustal thickness and support of topography on Venus. Journal of Geophysical Research: Planets, 118: 859875. doi:10.1029/2012JE004237.

Jeffreys, H. (Sir). 1924. The Earth-Its Origin, History and Physical Constitution. Cambridge University Press, Cambridge.

Kargel, J.S. 2013. Mercury's hollows: Chalcogenide pyro-thermokarst analog of thermokarst on Earth, Mars, and Titan. Lunar and Planetary Science, 44: Abstract 2840.

Kley, J. 2013, Saxonische Tektonik im 21. Jahrhundert: Zeitschrift der Deutschen Geologischen Gesellschaft, 164: 295-311.

Klimczak, C. 2015. Limits on the brittle strength of planetary lithospheres undergoing global contraction. Journal of Geophysical Research: Planets, 120: 2135-2151. doi:10.1002/(ISSN)2169-9100.

Klimczak, C., Watters, T.R., Ernst, C.M., Freed, A.M., Byrne, P.K., Solomon, S.C., et al. 2012. Deformation associated with ghost craters and basins in volcanic smooth plains on Mercury: Strain analysis and implications for plains evolution. Journal of Geophysical Research, 117: E00L03. doi:10.1029/2012JE004100.

Klimczak, C., Byrne, P.K., and Solomon, S.C. 2015. A rock-mechanical assessment of Mercury's global tectonic fabric. Earth and Planetary Science Letters, 416: 82-90. doi:10.1016/j.epsl.2015.02.003.

Klimczak, C., Kling, C.L., and Byrne, P.K. 2018. Topographic expressions of large thrust faults on Mars. Journal of Geophysical Research: Planets, 123: 19731995. doi:10.1029/2017JE005448.

Kober, L. 1921. Der Bau der Erde. Gebrüder Borntraeger, Berlin.

Kober, L. 1931. Das Alpine Europa. Gebrüder Borntraeger, Berlin.

Kober, L. 1942. Tektonische Geologie. Gebrüder Borntraeger, Berlin.

Kohlstedt, D.L., and Mackwell, S.J. 2010. Strength and deformation of planetary lithospheres. In Planetary Tectonics. Edited by T.R. Watters and R.A. Schultz. Cambridge University Press, Cambridge, UK pp. 397-456.

Kohlstedt, D.L., Evans, B., and Mackwell, S.J. 1995. Strength of the lithosphere: constraints imposed by laboratory experiments. Journal of Geophysical Research: Solid Earth, 100: 17587-17602. doi:10.1029/95JB01460.

Kreslavsky, M.A., and Basilevsky, A.T. 1998. Morphometry of wrinkle ridges on Venus: Comparison with other planets. Journal of Geophysical Research: Planets, 103: 11103-11111. doi:10.1029/98JE00360.

Kumar, P.S. 2005. An alternative kinematic interpretation of Thetis Boundary Shear Zone, Venus: Evidence for strike-slip ductile duplexes. Journal of Geophysical Research, 110: E07001. doi:10.1029/2004JE002387.

Lobeck, A.K. 1939. Geomorphology—An Introduction to the Study of Landforms. McGraw-Hill, New York and London.

Mackwell, S.J., Zimmerman, M.E., and Kohlstedt, D.L. 1998. High-temperature deformation of dry diabase with application to tectonics on Venus. Journal of Geophysical Research, 103: 975-984. doi:10.1029/97JB02671.

Masson, P. 1977. Structure pattern analysis of the Noctis Labyrinthus-Valles Marineris regions of Mars. Icarus, 30: 49-62. doi:10.1016/0019-1035(77)90120-8.

Masursky, H., Colton, G.W., and El-Baz, F. 1978. Apollo over the Moon: A View from Orbit. NASA Special Publication SP-362. Washington, DC.
Masursky, H., Eliason, E., Ford, P.G., McGill, G.E., Pettengill, G.H., Schaber, G.G., and Schubert, G. 1980. Pioneer Venus radar results: Geology from images and altimetry. Journal of Geophysical Research, 85: 8232-8260. doi:10.1029/ JA085iA13p08232.

Matthews, V. 1978. Laramide folding associated with basement block faulting in the western United States. Geological Society of America Memoir, 151. Boulder, Colo.

McKenzie, D., and Nimmo, F. 1999. The generation of Martian floods by the melting of ground ice above dykes. Nature, 397: 231-233. doi:10.1038/16649. PMID:9930697.

Mège, D., and Masson, P. 1996. Amounts of crustal stretching in Valles Marineris, Mars. Planetary and Space Science, 44: 749-781. doi:10.1016/0032-0633(96) 00013-X.

Mège, D., Cook, A.C., Garel, E., Lagabrielle, Y., and Cormier, M.-H. 2003. Volcanic rifting at Martian grabens. Journal of Geophysical Research, 108: 5044. doi: 10.1029/2002JE001852.

Mueller, K., and Golombek, M. 2004. Compressional structures on Mars. Annual Review of Earth and Planetary Sciences, 32: 435-464. doi:10.1146/annurev. earth.32.101802.120553.

Mueller, K., Vidal, A., Robbins, S., Golombek, M., and West, C. 2014. Fault and fold growth of the Amenthes uplift: Implications for Late Noachian crustal rheology and heat flow on Mars. Earth and Planetary Science Letters, 408: 100-109. doi:10.1016/j.epsl.2014.09.047.

Nahm, A.L., and Schultz, R.A. 2011. Magnitude of global contraction on Mars from analysis of surface faults: Implications for martian thermal history. Icarus, 211: 389-400. doi:10.1016/j.icarus.2010.11.003.

Okubo, C.H. 2010. Structural geology of Amazonian-aged layered sedimentary deposits in southwest Candor Chasma, Mars. Icarus, 207: 210-225. doi:10. 1016/j.icarus.2009.11.012.

Okubo, C.H., and Schultz, R.A. 2006. Variability in Early Amazonian Tharsis stress state based on wrinkle ridges and strike-slip faulting. Journal of Structural Geology, 28: 2169-2181. doi:10.1016/j.jsg.2005.11.008.

Padovan, S., Wieczorek, M.A., Margot, J.-L., Tosi, N., and Solomon, S.C. 2015, Thickness of the crust of Mercury from geoid-to-topography ratios. Geophysical Research Letters, 42: 1029-1038. doi:10.1002/2014GL062487.

Passchier, C.W., and Trouw, R.A.J. 2005. Microtectonics. Springer, Berlin, Germany.

Pasyanos, M.E. 2010. Lithospheric thickness modeled from long-period surface wave dispersion. Tectonophysics, 481: 38-50. doi:10.1016/j.tecto.2009.02.023.

Pechmann, J.B., and Melosh, H.J. 1979. Global fracture patterns of a despun planet: Application to Mercury. Icarus, 38: 243-250. doi:10.1016/0019-1035 (79)90181-7.

Plescia, J.B. 1991. Wrinkle ridges in Lunae Planum Mars: Implications for shortening and strain. Geophysical Research Letters, 18: 913-916. doi:10.1029/ 91GL01070.

Plescia, J.B. 1993. Wrinkle ridges of Arcadia Planitia, Mars. Journal of Geophysical Research, 98: 15049-15059. doi:10.1029/93JE01324.

Plescia, J.B., and Golombek, M.P. 1986. Origin of planetary wrinkle ridges based on the study of terrestrial analogs. Geological Society of America Bulletin, 97: 1289-1299. doi:10.1130/0016-7606(1986)97<1289:OOPWRB>2.0.CO;2.

Pollard, D.D., and Aydin, A. 1988. Progress in understanding jointing over the past century. Geological Society of America Bulletin, 100: 1181-1204. doi:10. 1130/0016-7606(1988)100<1181:PIUJOT>2.3.CO;2.

Richter, H. 1983. Carl Ritter Werk und Wirkungen-Beiträge eines Symposiums im 200. Geburtsjahr des Gelehrten, Quedlinburg, DDR. VEB Hermann Haack Geographisch-Kartographische Anstalt, Gotha, 254 pp.

Rothery, D.A., and Massironi, M. 2010. Beagle Rupes - Evidence for a basal decollement of regional extent in Mercury's lithosphere. Icarus, 209: 256261. doi:10.1016/j.icarus.2009.12.009.

Schaber, G.G., Strom, R.G., Moore, H.J., Soderblom, L.A., Kirk, R.L., Chadwick, D.J., et al. 1992. Geology and distribution of impact craters on Venus: What are they telling us? Journal of Geophysical Research, 97:13257-13301. doi:10.1029/ 92JE01246.

Schultz, R.A. 1993. Brittle strength of basaltic rock masses with applications to Venus. Journal of Geophysical Research, 98: 10883-10895. doi:10.1029/ 93JE00691.

Schultz, R.A. 2000. Localization of bedding plane slip and backthrust faults above blind thrust faults: Keys to wrinkle ridge structure. Journal of Geophysical Research, 105: 12035-12052. doi:10.1029/1999JE001212.

Schultz, R.A., and Fossen, H. 2008. Terminology for structural discontinuities. American Association of Petroleum Geologists Bulletin, 92: 853-867. doi:10. 1306/02200807065.

Schultz, R.A., and Tanaka, K.L. 1994. Lithospheric-scale buckling and thrust structures on Mars: The Coprates rise and south Tharsis ridge belt. Journal of Geophysical Research, 99: 8371-8385. doi:10.1029/94JE00277.

Schultz, R.A., Okubo, C.H., Goudy, C.L., and Wilkins, S.J. 2004. Igneous dikes on Mars revealed by Mars Orbiter Laser Altimeter topography. Geology, 32: 889-892. doi:10.1130/G20548.1.

Schultz, R.A., Soliva, R., Okubo, C.H., and Mège, D. 2010. Fault populations. In Planetary Tectonics. Edited by T.R. Watters and R.A. Schultz. Cambridge University Press, Cambridge, UK pp. 457-510. doi:10.1017/CBO9780511691645.

Şengör, A.M.C. 1990a. Lithotectonic terranes and the plate tectonic theory of orogeny: A critique of the principles of terrane analysis. Circum-Pacific Coun- 
cil for Energy and Mineral Resources 2009 - Terrane Analysis of China and the Pacific Rim, 13: 9-46.

Şengör, A.M.C. 1990b. Plate tectonics and orogenic research after 25 years: A Tethyan perspective. Earth-Science Reviews, 27: 1-201. doi:10.1016/00128252(90)90002-D.

Şengör, A.M.C., and Jones, I.C. 1975. A new interpretation of Martian tectonics with special reference to the Tharsis region. In Geological Society of America Abstracts with Programs, 7: 1264.

Şengör, A.M.C., Natal'in, B.A., and Burtman, V.S. 1993. Evolution of the Altaid tectonic collage and Palaeozoic crustal growth in Eurasia. Nature, 364: 299307. doi:10.1038/364299a0.

Şengör, A.M.C., Acar, D., Özeren, M.S., Ülgen, S.C., Önsel, İ.E., Öne, A.T., et al. 2016. Valles Marineris and the Martian chasmata as thermokarstic poljes. Lunar and Planetary Science, 47: Abstract 2257.

Şengör, A.M.C., Natal'in, B.A., Sunal, G., and van der Voo, R. 2018. The tectonics of the Altaids: Crustal growth during the construction of the continental lithosphere of central Asia between $\sim 750$ and $\sim 130$ Ma ago. Annual Review of Earth and Planetary Sciences, 46: 439-494. doi:10.1146/annurev-earth060313-054826.

Sibson, R.H. 1990. Rupture nucleation on unfavorably oriented faults. Bulletin of the Seismological Society of America, 80: 1580-1604.

Sleep, N.H. 1994. Martian plate tectonics. Journal of Geophysical Research, 99: 5693-5655. doi:10.1029/94JE00216.

Solomon, S.C. 1977. The relationship between crustal tectonics and internal evolution in the Moon and Mercury. Physics of the Earth and Planetary Interiors, 15: 135-145. doi:10.1016/0031-9201(77)90026-7.

Solomon, S.C., Head, J.W., Kaula, W.M., McKenzie, D., Parsons, B., Phillips, R.J., et al. 1991. Venus tectonics: Initial analysis from Magellan. Science, 252: 297-312. doi:10.1126/science.252.5003.297. PMID:17769277.

Solomon, S.C., Smrekar, S.E., Bindschadler, D.L., Grimm, R.E., Kaula, W.M., McGill, G.E., et al. 1992. Venus tectonics: An overview of Magellan observations. Journal of Geophysical Research, 97: 13199-13255. doi:10.1029/ 92JE01418.

Sonder, R.A. 1947. Discussion of "Shear patterns of the earth's crust" by F. A. Vening Meinesz. Transactions of the American Geophysical Union, 28: 939-946. doi:10. 1029/TR028i006p00939.

Sonder, R.A. 1956. Mechanik der Erde. Schweizerbart'sche Verlagsbuchhandlung, Stuttgart.

Squyres, S.W., Jankowski, D.G., Simons, M., Solomon, S.C., Hager, B.H., and McGill, G.E. 1992. Plains tectonism on Venus: The deformation belts of Lavinia Planitia. Journal of Geophysical Research, 97: 13579-13599. doi:10. 1029/92JE00481.

Staub, R. 1924. Der Bau der Alpen. Beiträge Zur Geologischen Karte der Schweiz, 52: 272 pp.

Staub, R. 1928. Der Bewegungsmechanismus der Erde - dargelegt am Bau der irdischen Gebirgssysteme. Gebruder Borntraeger, Berlin.

Stille, H. 1920. Über Alter und Art der Phasen variszischer Gebirgsbildung. Nachrichten von der Gesellschaft der Wissenschaften zu Göttingen. Mathematisch-Physikalische Klasse, Heft 2: 218-224.

Stille, H. 1924. Grundfragen der Vergleichenden Tektonik: Gebrüder Borntraeger, Berlin.

Stille, H. 1930. Über Einseitigkeiten in der Germanotypen Tektonik Nordspaniens und Deutschlands. Nachrichten von der Gesellschaft der Wissenschaften zu Göttingen. Mathematisch-Physikalische Klasse, Fachgruppe IV (Geologie und Mineralogie), 5: 379-397.

Stille, H. 1940. Einfuhrung in den Bau Amerikas. Gebruder Borntraeger, Berlin.

Stone, D.S. 1993. Basement-involved thrust-generated folds as seismically imaged in the subsurface of the central Rocky Mountain foreland. Geological Society of America Special Papers, 280: 271-318. doi:10.1130/SPE280-p271.

Strom, R.G., Trask, N.J., and Guest, J.E. 1975. Tectonism and volcanism on Mercury. Journal of Geophysical Research, 80: 2478-2507. doi:10.1029/JB080i017p02478.

Stuurman, C.M., Osinski, G.R., Holt, J.W., Levy, J.S., Brothers, T.C., Kerrigan, M., and Campbell, B.A. 2016. SHARAD detection and characterization of subsurface water ice deposits in Utopia Planitia, Mars. Geophysical Research Letters, 43: 9484-9491. doi:10.1002/2016GL070138.

Suess, E. 1868. Bemerkungen über die Lagerung des Salzgebirges bei Wieliczka: Sitzungsberiche der Kaiserlichen Akademie der Wissenschaften mathematischnaturwissenschaftliche Klasse, 58: 541-547.

Suess, E. 1875. Die Entstehung der Alpen. W. Braumüller, Wien.

Suess, E. 1883. Das Antlitz der Erde, Bd. Ia (Erste Abtheilung). F. Tempsky, Prag and G. Freytag, Leipzig.

Suess, E. 1885. Das Antlitz der Erde, Bd. Ib. F. Tempsky, Prag and G. Freytag, Leipzig.

Suess, E. 1888. Das Antlitz der Erde, Bd. II. F. Tempsky, Prag and Wien, and G. Freytag, Leipzig.

Suess, E. 1901. Das Antlitz der Erde, Bd. III1 (Dritter Band. Erste Hälfte). F. Tempsky, Prag and Wien, and G. Freytag, Leipzig.

Suess, E. 1909a. Das Antlitz der Erde, Bd. III2 (Dritter Band. Zweite Hälfte. Schluss des Gesamtwerkes). F. Tempsky, Wien and G. Freytag, Leipzig.

Suess, E. 1909b. The Face of the Earth (Das Antlitz der Erde), v. IV. Clarendon Press, Oxford.
Suess, E. 1918. La Face de la Terre (Das Antlitz der Erde), traduit de l'Allemand, avec l'autorisation de l'auteur et annoté sous la direction de Emm. De Margerie, tome III (4e partie \{Fin\}): Armand Colin, Paris.

Turcotte, D., and Schubert, G. 2002. Geodynamics. Cambridge University Press, Cambridge UK.

Vasavada, A.R., Paige, D.A., and Wood, S.E. 1999. Near-surface temperatures on Mercury and the Moon and the stability of polar ice deposits. Icarus, 141: 179-193. doi:10.1006/icar.1999.6175.

Vening Meinesz, F.A. 1947. Shear patterns of the earth's crust. Transactions, American Geophysical Union, 28: 1-61. doi:10.1029/TR028i001p00001.

von Buch, L. (Baron). 1810. Reise nach Norwegen und Lappland, zweiter Theil. In Leopold von Buch's Gesammelte Schriften (vol. 2). Edited by J. Ewald, J. Roth, and W. Dames (1870). G. Reimer, Berlin, pp. 357-563.

von Buch, L. (Baron). 1824. Ueber die geognostischen Systeme von Deutschland Ein Schreiben an den Geheimrath v. Leonhard. V. Leonhards Mineralogisches Taschenbuch fur das Jahr 1824, pp. 501-506.

von Humboldt, A. (Baron). 1823a. Essai Géognostique sur le Gisement des Roches dans les Deux Hémisphères. F. G. Levrault, Paris, viij + 379 p.

von Humboldt, A. (Baron). 1823b. Ueber den Bau und die Wirkungsart der Vulkane in verschiedenen Erdstrichen. Akademie der Wissenschaften zu Berlin, 1822/23. Berlin, 1825: 138-155.

von Humboldt, A. (Baron). 1831. Fragmens de Géologie et de Climatologie Asiatiques, tome premier. Gide, A. Pihan Delaforest, Delaunay, Paris, 309 p.

von Humboldt, A. (Baron). 1843. Asie Centrale - Recherches sur les Chaînes des Montagnes et la Climatologie Comparée, tome premier. Gide, Paris, LVIII + 571 p.

von Richthofen, F. (Baron). 1903. Geomorphologische Studien aus Ostasien. IV. Über Gebirgskettungen in Ostasien, mit Anschluss von Japan. V. Gebirgskettungen im japanischen Bogen. Sitzungsberichte der königlich preussischen Akademie der Wissenschaften, Sitzung der physikalisch-mathematischen Classe vom 30. Juli, 40: 867-918.

Watters, T.R. 1988. Wrinkle ridge assemblages on the terrestrial planets. Journal of Geophysical Research, 93: 10236-10254. doi:10.1029/JB093iB09p10236.

Watters, T.R. 1989. Periodically spaced anticlines of the Columbia Plateau, Geological Society of America Special Papers, 238: 283-292. doi:10.1130/spe239p283.

Watters, T.R. 1991. Origin of periodically spaced wrinkle ridges on the Tharsis Plateau of Mars. Journal of Geophysical Research, 96: 15599-15616. doi:10. 1029/91JE01402.

Watters, T.R. 1993. Compressional tectonism on Mars. Journal of Geophysical Research, 98: 17049-17060. doi:10.1029/93JE01138.

Watters, T.R., and Nimmo, F. 2010. The tectonics of Mercury. Edited by T.R. Watters and R.A. Schultz. Cambridge University Press, Cambridge, UK pp. 15-80. doi:10.1017/CBO9780511691645.

Watters, T.R., Cook, A.C., and Robinson, M.S. 2001. Large-scale lobate scarps in the southern hemisphere of Mercury. Planetary and Space Science, 49: 15231530. doi:10.1016/S0032-0633(01)00090-3.

Watters, T.R., Solomon, S.C., Robinson, M.S., Head, J.W., André, S.L., Hauck, S.A., II, and Murchie, S.L. 2009. The tectonics of Mercury: The view after MESSENGER's first flyby. Earth and Planetary Science Letters, 285: 283296. doi:10.1016/j.epsl.2009.01.025.

Weiss, D.K., and Head, J.W. 2017. Evidence for stabilization of the ice-cemented cryosphere in earlier Martian history: Implications for the current abundance of groundwater at depth on Mars. Icarus, 288: 120-147. doi:10.1016/j. icarus.2017.01.018.

Wernicke, B. 1995. Low-angle normal faults and seismicity: A review. Journal of Geophysical Research, 100: 20159-20174. doi:10.1029/95JB01911. doi:, 10.1029/ 95JB01911.

Wickham, J. 1995. Fault displacement-gradient folds and the structure at Lost Hills, California (USA). Journal of Structural Geology, 17: 1293-1302. doi:10. 1016/0191-8141(95)00029-D.

Williams, J.-P., Ruiz, J., Rosenburg, M.A., Aharonson, O., and Phillips, R.J. 2011. Insolation driven variations of Mercury's lithospheric strength. Journal of Geophysical Research, 116: E01008. doi:10.1029/2010JE003655.

Wilson, J.T. 1954. The development and structure of the crust. In The Earth as a Planet: The Solar System II. Edited by G.P. Kuiper. The University of Chicago Press, Chicago, pp. 138-214.

Wilson, J.T. 1965. A new class of faults and their bearing on continental drift. Nature, 207: 343-347. doi:10.1038/207343a0.

Yin, A. 2012. An episodic slab-rollback model for the origin of the Tharsis rise on Mars: Implications for initiation of local plate subduction and final unification of a kinematically linked global plate-tectonic network on Earth. Lithosphere, 4: 553-593. doi:10.1130/L195.1.

Ziegler, P.A., Cloetingh, S., and van Wees, J.-D. 1995. Dynamics of intra-plate compressional deformation: The Alpine foreland and other examples. Tectonophysics, 252: 7-59. doi:10.1016/0040-1951(95)00102-6.

Zoback, M.D. 2007. Reservoir Geomechanics. Cambridge University Press, Cambridge, UK.

Zuber, M.T. 1995. Wrinkle ridges, reverse faulting, and the depth penetration of lithospheric strain in Lunae Planum, Mars. Icarus, 114: 80-92. doi:10.1006/ icar.1995.1045. 